Florida International University FIU Digital Commons

$10-29-2007$

\title{
Effects of a short-term freeze on Sphagnum girgensohnii grown under different light- temperature regimes
}

Jane Sarah Colby

Florida International University

DOI: $10.25148 /$ etd.FI14060873

Follow this and additional works at: https://digitalcommons.fiu.edu/etd

Part of the Biology Commons

\section{Recommended Citation}

Colby, Jane Sarah, "Effects of a short-term freeze on Sphagnum girgensohnii grown under different light-temperature regimes" (2007). FIU Electronic Theses and Dissertations. 2403.

https://digitalcommons.fiu.edu/etd/2403 


\title{
FLORIDA INTERNATIONAL UNIVERSITY
}

\author{
Miami, Florida
}

EFFECTS OF A SHORT-TERM FREEZE ON

SPHAGNUM GIRGENSOHNII GROWN UNDER DIFFERENT LIGHT-

TEMPERATURE REGIMES

A thesis submitted in partial fulfillment of the

requirements for the degree of

MASTER OF SCIENCE

in

BIOLOGY

by

Sarah Jane Colby 
To: Interim Dean Mark Szuchman

College of Arts and Sciences

This thesis, written by Sarah Jane Colby, and entitled Effects of a short-term freeze on Sphagnum girgensohnii grown under different light-temperature regimes, having been approved in respect to style and intellectual content, is referred to you for judgment.

We have read this thesis and recommend that it be approved.

Jennifer H. Richards

Michael S. Ross

Steven F. Oberbauer, Major Professor

Date of Defense: October 29, 2007

The thesis of Sarah Jane Colby is approved.

Interim Dean Mark Szuchman

College of Arts and Sciences

Dean George Walker

University Graduate School

Florida International University, 2007 
(C) Copyright 2007 by Sarah Jane Colby

All rights reserved. 


\section{DEDICATION}

For my mom and my dad: together they embody all that is good in the world. 


\section{ACKNOWLEDGMENTS}

This thesis was based on work supported by the National Science Foundation Office of Polar Programs under grant OPP-9907185. Research funding was also provided by the Florida International University Graduate Student Association Research Funding Program.

I want to express my sincerest gratitude to the Department of Biological Sciences. The faculty and graduate student community provided a rich and engaging environment. I want to thank the Plant Ecophysiology Lab for countless stimulating conversations. Chad Husby, fellow labmate, deserves an extra thank you for sharing many hours of his statistical gifts with me. Steve Turner, manager of the F.I.U. Greenhouse, was very helpful during the repair and maintenance of the environmental growth chambers.

I would like to thank my committee members, Dr. Jennifer Richards and Dr. Michael Ross, for their careful review of my thesis. I have benefited much from the Dr. Richards' wealth of plant knowledge, and I appreciate the thoughtful conversations I have had with Dr. Ross, especially during the design of the experiment.

I will always be grateful to my major professor, Dr. Steven F. Oberbauer for allowing me to truly taste science and see some of the most beautiful places on Earth. He has made me a better writer, thinker, problem-solver, steward and teacher.

I would be remiss if I did not acknowledge the unwavering support of my family and friends. Through the ups and downs of these challenging years, they have remained there always. They could not have loved me more. 
ABSTRACT OF THE THESIS

EFFECTS OF A SHORT-TERM FREEZE ON SPHAGNUM GIRGENSOHNII GROWN UNDER DIFFERENT LIGHT- TEMPERATURE REGIMES

by

Sarah Jane Colby

Florida International University, 2007

Miami, Florida

Professor Steven F. Oberbauer, Major Professor

During the short, snow-free growing seasons in the Arctic, sudden "cold snaps" or freeze thaw events (FTE) frequently occur when temperatures fall subzero for 24 to $72 \mathrm{~h}$. Vascular plants exposed to FTE are often irreversibly damaged, but despite their importance, the responses of nonvascular plants to FTE have been little studied. I grew plants of Sphagnum girgensonhii under high and low light and temperature conditions to investigate whether pre-freeze conditions influence damage and recovery of this important moss species. Plants grown at low light and high temperature showed the greatest growth. Upon freezing they also showed irreversible physiological damage and the greatest reduction in growth. Furthermore, some growing conditions resulted in increased production of new branches that were lost during freezing. The findings of this study suggest that the responses of Sphagnum species to climate variation may be important for the structure of arctic plant communities. 
I. Global climate change and the genus Sphagnum: a review...................................

Climate change in Sphagnum-dominated ecosystems ......................................1

Sphagnum: key player in a carbon shift?

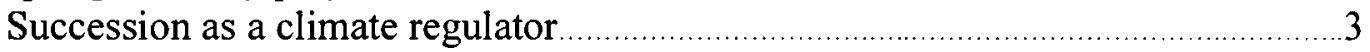

Response of Sphagnum to climate change: present understanding ..........................4

II. Freeze-thaw events negate the advantage of warm and shady growing environments for Sphagnum girgensohnii ................................................ 11

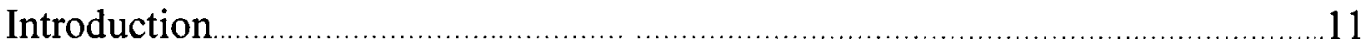

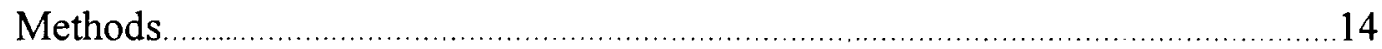

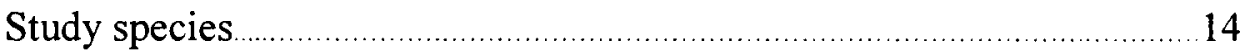

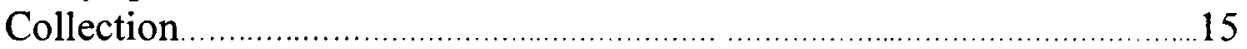

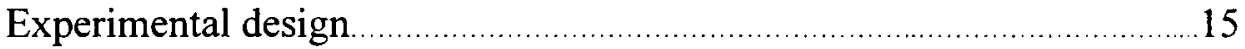

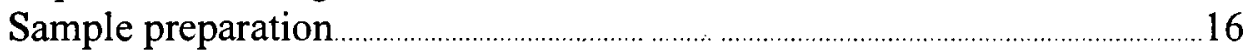

Growth chamber conditions .................................................................. 17

Sampling methods

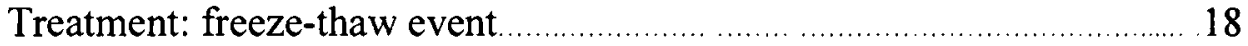

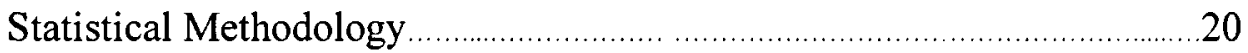

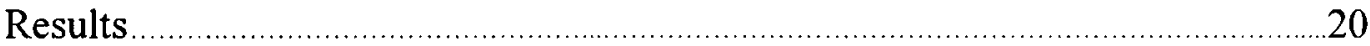

Light-temperature growing environments …........................................20

Changes in physiological activity in Sphagnum girgensohnii

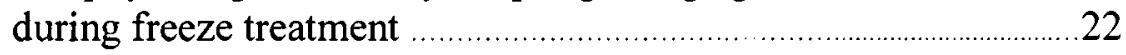

Rate of physiological recovery from a freeze-thaw event .....................23

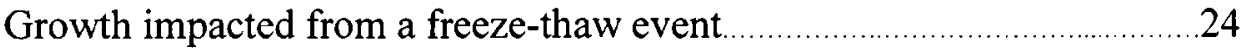

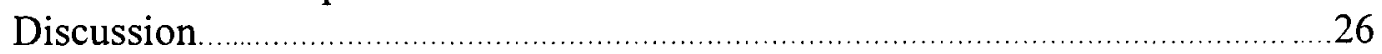

Preference for a low light-high temperature environment $\ldots \ldots \ldots \ldots \ldots \ldots \ldots \ldots \ldots . . .26$

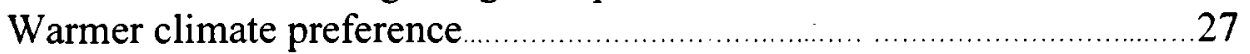

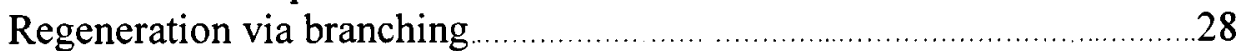

Changes in physiological activity in Sphagnum during a

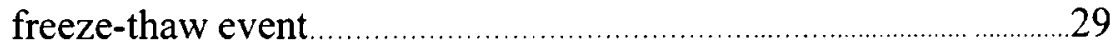

Sphagnum growth at low-temperature: physiologically vulnerable to

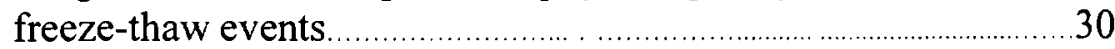

Freeze-thaw event: modes of growth and growing conditions

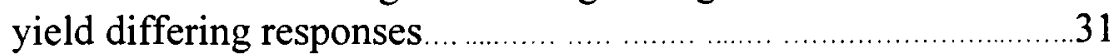

Warmer climate: Sphagnum loses ecosystem engineering ability ..............33

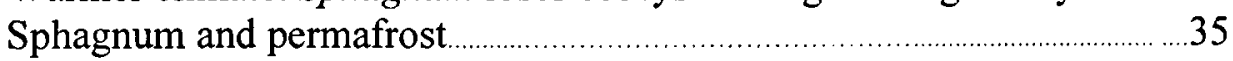

Freeze-thaw events as an ecosystem influence .......................................37

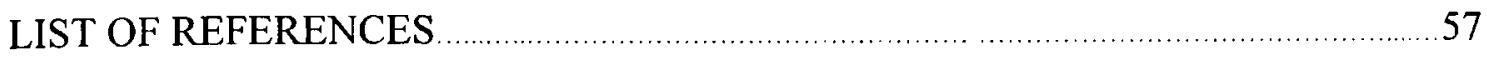




\section{LIST OF TABLES}

TABLE

PAGE

1. Analysis of variance of growth response to light and temperature 38

2. Analysis of variance of physiological response to light and temperature during 5 weeks of growth..

3. Analysis of variance of physiological response between Day 39 and Day 41 under light, temperature and FTE differences measured at $6^{\circ} \mathrm{C}$.

4. Analysis of variance of physiological difference between Day 36 and Day 46 .

5. Analysis of variance of physiological difference between Day 36 and Day 55 . 40

6. Analysis of variance of physiological difference between Day 46 and Day 55 . 40

7. Analysis of variance of growth response to a freeze-thaw event and interactions with light and temperature

8. Analysis of variance- Difference of least squares means of growth response comparison among light and temperature environments with and without a FTE

9. Analysis of variance- Difference of least squares means of growth response comparison between light-temperature environments with and without a FTE 


\section{LIST OF FIGURES}

FIGURE

PAGE

1. Experimental design

2. Regression of water content method using dummy samples

3. Temperature during the six independent subzero freezes

4. Growth response to four light-temperature environments

5. Physiological response to four light-temperature environments over 5 weeks

6. Short-term freeze effect on four light-temperature acclimation conditions

7. Recovery after FTE shown as measurements 1-Day before FTE minus post Day 5 and post Day 14

8. Freeze effect on the growth response under 4 light-temperature environments.

9. Warmer climate: Sphagnum loses the ecosystem engineering ability 


\section{LIST OF PLATES}

PLATE

PAGE

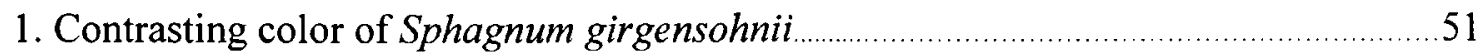

2. Toolik Lake, Brooks Range, AK: Collection location $\ldots$

3. Freeze-thaw event set-up

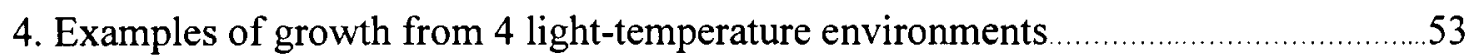

5. Sphagnum branches produced in the low-light, high-temperature environment ........54

6. Loss of chlorophyll in the tender new shoots due to the freeze-thaw event $\ldots \ldots \ldots \ldots \ldots . . .55$

7. Sphagnum girgensohnii Russowi under 300X S.E.M 


\section{CHAPTER I}

Global climate change and the genus Sphagnum: a review.

Sphagnum mires have been estimated to cover about 150 million hectares worldwide (Clymo and Hayward 1982), which equates to 120 billion metric tons of carbon (Longton 1992). Labeled as ecosystem engineers (Svensson 1995, Van Breeman 1995), Sphagnum mosses sequester nutrients that maintain these vast mires while providing a niche for many other acidophilic species. Predominately found in the higher latitudes, Sphagnumdominated peatlands facilitate the highest rates of carbon sequestion in boreal and polar regions (Berense et al. 2001). This accumulation of carbon allows these regions to act as atmospheric $\mathrm{CO}_{2}$ sinks (Gorham 1991) resulting from: 1) low belowground temperatures; 2) acidic conditions; 3) high soil moisture; 4) recalcitrant litter.

Here I highlight the importance of the genus Sphagnum to higher-latitude ecosystems. The role of Sphagnum mosses under climatic change is reviewed, outlining the current literature that examines the effects of altered environmental conditions on the growth and physiology of these bryophytes. Identifying the ecophysiological response of the genus Sphagnum is critical to understanding the ecosystem response of Sphagnum-dominated landscapes in this dynamic climate era.

Climate change in Sphagnum-dominated ecosystems.

While climate change is predicted to occur globally, climate models forecast the high latitudes to be the most severely impacted (IPCC 2001, Maxwell 1992). The Arctic, an extreme environment sensitive to climatic change (Maxwell 1992), is at considerable 
risk of vegetation changes under warmer conditions. Evidence is now accumulating that such changes are already occurring (Walker et al. 2006, Hinzman et al. 2005, Kulman 2002, Serreze et al. 2000). Perhaps even more critical, the potential of the Arctic to act as an additional source of carbon because of increased thawing of the permafrost, which leads to increased microbial activity and decomposition rates, has global repercussions (Marion et al. 1997, Oechel et al.1993, Koprivnjak \& Moore 1992).

Research that examines physiological responses of arctic tundra plants may provide insight as to the consequences of climatic change in the northern latitudes. Sphagnum mosses compose a significant portion of the arctic vegetation (Hobbie et al. 2000; Walker et al. 1989). Hastings et al. (1989) estimated that Sphagnum accounts for approximately $27.6 \%$ of live plant biomass in the low Arctic, indicating the importance of understanding the ecosystem role of this genus.

Sphagnum: key player in a carbon shift?

Sphagnum and other mosses not only act as ecological indicators of the intensity of climatic changes (Andrus et al. 1992), but may also be critical regulators of the impact that climate change has on tundra. Sphagnum, accounting for a substantial amount of the tundra understory, acts as the interface between aboveground climatic variables and belowground processes. If Sphagnum growth responds positively to climate change, then the potential of the melting permafrost layer acting as a carbon source may be minimized. Because of its ability to insulate the permafrost layer and to store carbon (Vitt et al. 1994), Sphagnum may thereby act as a negative feedback that will compensate for a change in the carbon balance. Oechel \& Vourlitis (1994) proposed a similar argument that the Arctic may at first act as a source of carbon, but then selectively adapt to the 
increase in available nutrients, ultimately transforming back into a carbon sink.

Likewise, if Sphagnum growth and photosynthetic rates are negatively impacted by climate change, then Sphagnum could act as a positive feedback of climate warming. This positive feedback could exacerbate carbon release by speeding up peat decomposition rates and lowering permafrost depths. Further research needs to be geared towards understanding the photosynthetic and growth responses of Sphagnum to the multiple climatic changes that are predicted to occur (Hobbie et al. 2000).

Succession as a climate regulator.

The ability of Sphagnum to dominate a landscape has prompted discussion of the role of Sphagnum in succession. Traditionally, Sphagnum species are thought to be responsible for the succession process of converting water bodies to dry land (Longton 1992), allowing vascular plants and then forests to colonize the area. In the Arctic where the climate is severe, Sphagnum may be an example of Muller's (1952) auto succession, where climatic factors hold competition to a minimum and thereby allow Sphagnum species to maintain occupancy in the community. Additionally, some researchers have described the role of Sphagnum as that of an ecosystem engineer (Heijmans et al. 2001; Svensson 1995; Van Breemen 1995), where Sphagnum is sequestering nutrients to maintain its status rather than creating an environment more suitable to vascular plants that would facilitate the succession process. During a fertilization experiment, Svensson (1995) found that the vascular rosette plant, Drosera rotundifolia, responded with vertical growth only when Sphagnum challenged it with its own vertical growth, which may indicate that vascular bog plants are not adapted to the advancing of the dominating 
Sphagnum. Alternatively, Ohlson et al. (2001) recently reported that Sphagnum mosses may be out-competed by the early succession of Scot pine. These conflicting findings suggest that Sphagnum in the Arctic is at a growth-rate equilibrium with its present vascular competitors, but this equilibrium may be at considerable risk if climate warming shifts the growth balance among species or allows the introduction of superior competitors. Knowledge of how Sphagnum growth rates vary under a variety of climate changes is crucial to understanding how climate change may affect the composition of the arctic landscape.

Response of Sphagnum to climate change: present understanding

Because of its abundance and role in the formation of mires, Sphagnum has long intrigued bryologists, and fundamental studies of Sphagnum physiology have been slowly accumulating for a century. In recent decades, studies have been geared towards examining the growth and physiology of Sphagnum under altered environmental conditions to gain insight into vegetative response to a range of habitats and recently to potential climate change scenarios (Mitchell et al. 2002, Searles et al. 2002, Berendse et al. 2001).

One global change already occurring at an exponential rate since the on-set of the western industrial revolution is the increase of atmospheric $\mathrm{CO}_{2}$, which has gone from $280 \mathrm{ppm}$ in the late 1800 's to current $379 \mathrm{ppm}$ by 2005 , and is expected to climb throughout this century (IPCC 2007). An increase in atmospheric $\mathrm{CO}_{2}$ may increase growth of some Sphagnum species. Heijmans et al. (2001) found that S. magellenicum length growth was correlated with increased $\mathrm{CO}_{2}$ levels. Jauhiainen et al. (1998) offer 
further support demonstrating a correlation between increased atmospheric $\mathrm{CO}_{2}$ and an increase in biomass, density and individual growth length of $S$. angustifolium and $S$. warnstorfii. This increase in growth of Sphagnum due to atmospheric $\mathrm{CO}_{2}$ could be compounded as well by additional $\mathrm{CO}_{2}$ availability in moss mats originating belowground as the permafrost layer thaws. Berendse and colleagues (2001) found, however, that an increase in atmospheric $\mathrm{CO}_{2}$ did not influence the growth of Sphagnum in four high latitude locations across Western Europe. These conflicting studies can be reconciled by the findings that the response of Sphagnum species to increases in $\mathrm{CO}_{2}$ can differ regionally, a further consideration that may be important when estimating the changing carbon budgets.

Further, interspecific growth-rate differences within the genus may also occur, which could lead to genus-level community structure shifts in peatland regions (Mulligan \& Gignac 2002, 2001). Increases in atmospheric $\mathrm{CO}_{2}$ may cause broad shifts in plant community structure by altering existing competition dynamics. Keeling et al. (1996) showed that a shift in the annual $\mathrm{CO}_{2}$ concentration pattern provides evidence that the growing season is lengthening, especially in the Arctic.

In addition to carbon, the melting permafrost layer may also release stored nitrogen, commonly thought to be a limiting factor for Arctic plants (Aldous 2002, Gunnarson \& Rydin 2000). A change in belowground nitrogen may influence existing interspecific competition between and among vascular and non-vascular species. Research has suggested that Sphagnum growth (Berendse et al. 2001; Heijmans et al. 2001; Gunnarsson \& Rydin 2000; Hogg et al. 1995) and biomass (Van DerHeijden et al. 2000) decreases with increased available nitrogen. Thus a melting permafrost layer 
increasing available nitrogen may cause Sphagnum to act as a source of carbon as the tundra warms. Changes in hydrology may also affect the ability of Sphagnum to retain N (Aldous 2002).

Climate change is anticipated to alter precipitation patterns worldwide (IPPC 2007, Dore 2005). The level of the soil water table is directly influenced by changes in the precipitation and temperature. In the Arctic, Kane et al. (1992) argue that thawing of the permafrost layer via global warming will lower the water table level, thereby lowering the moisture level of the active layer. Hayward and Clymo (1983) have shown that such a lowered water table has a negative effect on individual elongation of the stem of three species of Sphagnum, but collectively the growth of peat lawn increases. Earlier, however, Clymo (1973) found that increased Sphagnum biomass and length growth is highly correlated with a declining water table. Confounding the issue, an increase in precipitation, which is predicted as a possible result of arctic warming in the Canadian Centre for Climate Prediction and Analysis (CCC) model (Maxwell 1992), may increase water table levels. Since Sphagnum thrives in very moist locales such as watertracks, a higher water table could translate into increased growth of Sphagnum species (Moorhead \& Reynolds 1993). Additionally, any change in the water table level is likely to affect Sphagnum species differently (Grosvernier et al. 1997; Hayward \& Clymo 1983), and therefore could result in an altered composition of plant community and the Sphagnumvascular plant competitive balance. However, changes in precipitation, evaporation, and active layer depth may nullify each other, and result in no net water table change (Gerol et al. 1998), and thus climate change would not affect Sphagnum through effects of the water table. 
Light intensity is considered a key driving ecological component in many landscapes, and climate change is predicted to alter moss light environments via increased cloudiness (IPCC 2001) and/or changes in plant canopy structures (Hollister et al. 2005), which will affect light availability for understory species such as Sphagnum. Like all plants, a minimum light level is required for growth of Sphagnum, but the genus has a remarkable feature in which seemingly dead, old stems that are buried in a peat matrix can establish new shoots once minimum light requirements are met (Clymo \& Duckett 1986). However, minimum light levels for growth activity to occur in Sphagnum species have not been yet determined. Haywood and Clymo (1983) concluded that higher light intensity positively correlated with higher elongation rates. Furthermore, within this generalization, they found that low light intensity on individuals of Sphagnum that resulted from shading by neighboring Sphagnum without any shading higher in the canopy, produced an increase in growth of neighbor-shaded individuals. Within the genus, this explains the community mechanism that allows individuals to regulate one another to grow in the typical mat formation (Haywood \& Clymo 1983). In comparison to other mosses, Sphagnum species have been noted to fall on the upper end of a light saturation range from 380 to $700 \mu \mathrm{mol} \mathrm{m}^{-2} \mathrm{~s}^{-1}$ (Skre \& Ochel 1981). At saturation however, light can become deleterious. Murray et al. (1993) showed that Sphagnum at $800 \mu \mathrm{mol} \mathrm{m}^{-2} \mathrm{~s}^{-1}$ is photoinhibited as indicated by a decrease in chlorophyll fluorescence, suggesting that Sphagnum may be inhibited if climate change resulted in an extended growing season or decreased vascular cover. Removing snow and thereby increasing light early in the growing season has been found to have similar negative response on an arctic Sphagnum-dominated community (S.F. Oberbauer, unpublished data). 
Global annual average temperature has already increased approximately $0.6^{\circ} \mathrm{C}$ during the last century, and projections for the next century range from $1.4{ }^{\circ} \mathrm{C}$ to $5.8^{\circ} \mathrm{C}$ (IPCC 2001). Temperatures in some arctic regions may potentially increase three times the global average increase (IPCC 2001). Such increased temperatures in high latitudes may result in several direct ramifications including changes in permafrost, snow dynamics, plant phenology and physiology, evaporation and decomposition rates. Numerous circumpolar experiments have examined the response of arctic vegetation to warmer temperatures (Arft et al. 1999), as well as addressed the effects of environment variables that have been shifted due to warmer temperatures such as season length (Oberbauer et al. 2002, Starr et al. 2000, Oberbauer et al. 1998) and plant community dynamics (Walker et al. 2006).

Because temperature amplifies many other environmental variables, determining the effect that increased temperatures will have on Sphagnum mosses is a multidimensional problem. Harley et al. (1989) found that temperature and the photosynthetic rate of Sphagnum were positively correlated. Hobbie et al. (1999), however, showed through a long-term community warming experiment that non-vascular plants responded negatively to climatic warming. This negative response could have been a result of the inability of Sphagnum to utilize the increased net $\mathrm{N}$ mineralization caused by the warming (Hobbie 1996), or may be simply attributed to an increased proportion of growth in vascular vegetation in comparison to bryophyte populations, putting Sphagnum at a competitive disadvantage. Alternatively, Gerol et al. (1998) provide evidence that climate warming increases the growth rate of Sphagnum, but they make the point that no net accumulation of Sphagnum may occur because warming will also increase the rate of 
peat decomposition. Lastly, warming in the Arctic may also speed up snow melt, thereby lengthening the growing season. The effect of an extended growing season on Sphagnum, which is conditioned to the short Arctic growing season, has yet to be investigated.

Although the seasonality of warming in the Arctic remains unclear, winter temperature increases may not affect Sphagnum mosses unless warming diminishes snow cover, which typical acts as an insulator against harsh atmospheric temperatures. Under snow, surface temperatures of the bryophyte understory of the Arctic have been found to remain above $-10^{\circ} \mathrm{C}$ (S.F. Oberbauer, unpublished data). With in vivo measurements taken in Antarctica, Pannewitz and colleagues (2004) showed that under such insulation, photosynthetic activities may occur at low air temperatures when light levels are sufficient.

In late spring and summer, Sphagnum mosses and other bryophytes are exposed to a wide range of temperatures as they become snow-free (Stein et al. 1994). During the 3-month snow-free period, temperatures periodically plummet to subzero temperature for several hours to several days (Stein et al. 1994). For the period of a cold event, plants are exposed to temperatures that cause rapid freezing and thawing that could cause permanent damage. More variable weather patterns forecasted by climate change models (IPCC 2007) will continue, if not increase, the exposure of tundra plant communities to rapid freeze-thaw events. Periodic cold air outbreaks are not expected to necessarily decease in severity or frequency with warmer average temperatures (Vavrus et al. 2006). Furthermore, anticipated increases in daily average arctic temperatures (IPCC 2007) may 
result in the loss of cold-hardening and thus decrease the ability of plants to cope with sudden cold temperature conditions, as has been observed in Betula pubescens (Taulavuori, K.M.J. et al. 2004), Salix pulchra (Gorsuch \& Oberbauer 2002), Scots pine (Repo et al. 1996), and Vaccinium myrtillus (Taulavuori et al. 1997).

In this chapter, I have reviewed the potential responses of Sphagnum to singular changes of an array of environmental variables that may be altered directly or indirectly by global climate change. Most likely, the effect of climate change on peatland ecosystems, such as the arctic tundra, will not be driven solely by a single altered abiotic factor, but rather by diverse environmental variables, which will result in a net response that may or may not be regionally localized. Multiple environmental changes, for instance, may be responsible for the bryophyte community shift within the Finish forest floor that was observed between 1951-1995 (Mäkipää \& Heikkinen 2003). Because of the need to understand the net response, research investigating the effect of climate change on Sphagnum that involve the manipulation of multiple climatic factors are becoming more common (Berendse et al. 2001, Hobbie et al. 1999, Jauhiainen et al. 1998). In the next chapter, I take just such an approach to examine the response of Sphagnum to temperature, light, and a common occurring weather pattern, a brief freeze-thaw event. This study investigates whether the projected warm, cloudier arctic summers with increased vascular plant shading may induce acclimation within Sphagnum that would result in a reduced ability to cope with short periods of subzero temperatures. 


\section{CHAPTER II}

Freeze-thaw events negate the advantage of warm and shady growing environments for Sphagnum girgensohnii

\section{Introduction}

Global warming is predicted to strongly affect the high latitudes by increasing temperatures and altering weather patterns (Maxwell 1992, IPCC 2001). Evidence is now overwhelming that such changes are occurring (Hinzman et al. 2005, Serreze et al. 2000). Arctic and boreal plant communities have a comparatively short growing season that commonly includes periodic freeze events where subzero temperatures persists from a few hours to multiple days (Stein et al. 1994). More variable weather patterns forecasted by climate change models (IPCC 2001) will continue, if not increase, exposure of tundra plant communities to rapid freeze-thaw events. The LTER site at Toolik Lake underwent 55 FTEs during the growing seasons between 1988-2002, 30 of which lasted more than 1 day (Shaver \& Laundre 2003.) The absence of precipitation during 24 of the 55 FTEs offered no snow cover to insulate Sphagnum from subzero atmospheric temperatures. Furthermore, anticipated increases in daily average arctic temperatures (IPCC 2001) may result in acclimation that decreases the ability of plants to cope with sudden cold temperature conditions (Taulavuori et al. 2004, 1997, Repo et al.1996).

Studies of vascular plants have shown they often suffer irreparable tissue damage that persists for the remainder of the growing season or longer due to these freeze-thaw cycles (Mazur 1969). Nonvascular plant species, particularly moss in the genus Sphagnum, compose a large proportion of the arctic communities, but research exploring the response of nonvascular species to such freeze-thaw cycles is limited. Knowledge of 
how nonvascular plants react to FTEs and mechanisms and pathways that are involved in the response to these cycles is essential to the understanding of tundra ecosystem response to low temperatures during the growing season (Chapin 1992).

The proportion of bryophytes in plant communities increases at high latitudes indicating that these plants have a competitive edge in these regions (Tenhunen et al. 1992). Physiological mechanisms that allow them to survive under extreme cold temperatures are one aspect of that edge. Mazur (1969) comprehensively outlined how the freezing of plants is a multiple-step process where water freezes extracellularly first, then may progress to intercellular freezing, and finally to an intracellular freezing state. The occurrence of intracellular freezing within plant tissue results in irreversible damage. Bryophytes remain in the earlier stages of freezing longer than vascular plants because of a greater ability to supercool (Dilks \& Proctor 1975). Often Sphagnum is described as becoming 'concrete-like' when frozen (Stein et al. 1994). Because of the prevalence of a large quantity of extracellular water, the concrete appearance of Sphagnum may be a result of only extracellular water freezing, thereby avoiding frost damage. However, increased severity and/or length of a freeze may result in inter/intracellular ice formation that occurs at the on-set of frost damage.

An additional complication to freezing stress for bryophytes is that plants undergoing freezing often remain exposed to normal or even high light conditions. Some bryophytes are unaffected by high light, low temperature conditions. Lovelock et al. (1995) suggested that a photoinhibitory mechanism in the Antarctic moss Grimmia antarctici exists that allows the moss to recover from high light, subzero temperatures with little need for repair. Antarctic Polytrichum alpestre is another example of a 
nonvascular plant that can photosynthetically recover from deep freezes, but its resilience is temperature and water dependent (Kennedy 1993). A study by Deltoro and colleagues (1999) examined how the Mediterranean moss Leucodon sciuroides tolerates freeze-thaw cycles by dissipative pathways. They suggest that such mechanisms may be even more important to nonvascular species in high latitudes and altitudes where low temperatures during the growing season are frequent. Even though Sphagnum mosses, dominant in boreal, subarctic, and arctic regions, are evidently able to survive in low temperature, high light environments, the severity and intensity of these extremes may be influencing their productivity. Murray et al. (1993) found that high light alone decreased Sphagnum mosses productivity via photoinhibition of photosynthesis. In a separate study, Balagurova et al. (1996) showed that Sphagnum mosses are highly freeze resistant, yet their resistance is variable between species and habitat. Lethal temperatures occur at about $-20^{\circ} \mathrm{C}$ for those species examined.

The topic of temperature acclimation of plants has received much attention, initially to understand the physiology of plants, but more recently as a potentially important component of plant interactions with the factors affected by global climate change. Dicranum elongatum, a model arctic species by Hicklenton \& Oechel (1976), exhibited contrasting ability to temperature acclimate depending on population origin. Subarctic plants achieved temperature acclimation at a greater rate than those of arctic populations, which may suggest that favorable growing conditions optimize plasticity and physiological mechanisms that permit temperature acclimation.

Sphagnum is a significant component of arctic plant communities, accounting for approximately $27.6 \%$ of live plant biomass in the low Arctic (Hastings et al. 1989). 
Sphagnum species are key players in this system because of their ability to maintain shallow active layers and low decomposition rates, which contribute to ecosystem storage in the Arctic. Therefore, if freeze-thaw events significantly affect the growth and productivity of Sphagnum, then the frequency and severity of these events may influence the ability of the Arctic to store carbon.

Here, I postulate that the physiology of Sphagnum depends on the temperature and light during growth, and that favorable growing conditions will result in increased ability to respond to brief subzero exposure. Further, I hypothesize that Sphagnum is capable of fully recovering from a mild, short-term freeze. To test these hypotheses, I conducted a growth chamber experiment on Sphagnum girgensohni Russow, in which I determined: (1) the rate of growth and physiological activity under different temperature and light levels; (2) the overall ability to recover from a brief freeze-thaw event; and (3) the interaction of different growth conditions with a freeze-thaw response.

\section{Methods}

Study species

Sphagnum girgensohnii Russowi. is a medium-sized, robust species that has a five-star, flat-top capitulum. Classified as a green Sphagnum (Plate 1a), field observations during collection revealed that exposed $S$. girgensohnii at the study site commonly exhibited a brown hue with specks of green instead of being entirely green (Plate 1b). It is positively identified via its broad, tongue-shaped stem leaves with a distinctive torn edge. Branch leaves are acute and striated, and the hardy stems are frequently reddishbrown and can exhibit a characteristic snapping sound when broken. 


\section{Collection}

Seven $20 \mathrm{~cm}^{2}$ mats of Sphagnum were collected along the same hillside near Toolik Lake in the northern foothills of the Brooks Range, Alaska in July of 2002 (Plate 2). Sphagnum was taken from non-water track, moist dwarf-shrub tundra, typical of the Alaskan Arctic (Walker et al. 1994), with Eriophorum vaginatum, Betula nana, Salix pulchra, and Sphagnum species dominating ground cover. Mats were place into sealable bags and were taken to Florida International University within $24 \mathrm{~h}$ via a cooler, where they remained at $4{ }^{\circ} \mathrm{C}$ in a dark refrigerator until preparation.

\section{Experimental design}

The experimental design consisted of Sphagnum microcosms grown for approximately 6 weeks at two temperatures (high and low, hereafter HT and LT) and two light levels (high and low, hereafter HL and LL) prior to being subjected to a 2 day freeze, followed by a 2 week recovery period. The experiment used an identical pair of environmental growth chambers set at the appropriate temperatures and the light treatments were applied equally within the growth chambers. To replicate, the experiment was repeated twice more for a total of three experimental trials. Each replicated experiment ran for 8 weeks total (55 days). All growing condition combinations (highlight/high-temperature: HLHT; high-light/low-temperature: HLLT; low light/hightemperature: LLHT; low light- low temperature: LLLT) were replicated within each experimental trial. The duplicate group within each trial received an independent, artificial freeze-thaw event so that freezing was replicated a total of six times within the experiments (Figure 1). 


\section{Sample preparation}

Experimental treatments were applied to sample microcosms consisting of approximately 10-12 individual stems that were arranged in a density similar to that in situ in a $3 \mathrm{~cm}$ diameter centrifuge tube. From carefully dissected Sphagnum mats, individuals were separated and cut to precisely $3 \mathrm{~cm}$ in length including capitulum and stem, thereby harvesting the most productive portion of the individual. Any branching stems were removed to attribute any future branching to treatment effects. Samples contained individuals taken from multiple natural mats to minimize any genetic homogeneity within treatments or replications. Stems were selected to total to a mean of $0.113 \mathrm{~g}$ in estimated dry weight. To prepare one sample tube, $10-12$ individuals were soaked in deionized water for 20 minutes, spun in a OXO Softworks Salad Spinner (model 01045409) to standardize initial water content, and weighed to establish starting biomass (Clymo 1983). A regression was performed to examine the precision of the salad centrifuge method by weighing a subsample of spun plants, drying the samples for 48 hours at $70^{\circ} \mathrm{C}$, and recording the dry weight. The method was deemed acceptable for standardizing water content $\left(\mathrm{R}^{2}=0.92, \mathrm{n}=32\right.$, Figure 2$)$. Digital images were taken to document overall qualitative condition and color of each moss sample. Canadian peat moss (Scotts $\left.{ }^{\mathbb{R}}\right)$ served as the substrate in the tubes below the $3 \mathrm{~cm}$ length plants. The substrate was heated to $70^{\circ} \mathrm{C}$ for $48 \mathrm{~h}$ to destroy any potential competing foreign species. Sixteen sample tubes were prepared for each replicate of the experiment. 


\section{Growth chamber conditions}

A pair of EGC 15 growth chambers (Environmental Growth Chambers, Chagrin Falls, $\mathrm{OH}$ ) were used to provide the treatment conditions. One chamber was set at $12{ }^{\circ} \mathrm{C}$ for $18 \mathrm{~h}$ out of a $24 \mathrm{~h}$ period and $10^{\circ} \mathrm{C}$ for the remaining $6 \mathrm{~h}$. The substrate portion of the sample tubes was submerged in an icebath in the $12{ }^{\circ} \mathrm{C}$ chamber to simulate a shallow active layer. The second chamber was set at $18^{\circ} \mathrm{C}$ for $18 \mathrm{~h}$ and $14^{\circ} \mathrm{C}$ for $6 \mathrm{~h}$. In both chambers, light levels were maintained at $\sim 475 \mu \mathrm{mol} \mathrm{m} \mathrm{m}^{-1}$ photosynthetically active radiation for $18 \mathrm{~h}$ out of a $24 \mathrm{~h}$ period with high output fluorescent bulbs. Photoperiod was maintained at $24 \mathrm{~h}$ in both chambers by running one $100 \mathrm{~W}$ incandescent bulb continuously. Low light conditions $\left(\sim 325 \mu \mathrm{mol} \mathrm{m}^{-2} \mathrm{~s}^{-1}\right)$ were created by placing $50 \%$ shade cloth caps on four of the eight sample tubes in every chamber. All samples were saturated with deionized water daily; high-light samples received additional watering as needed to compensate for potential higher evaporation rates. Temperature and light levels in the chambers were checked daily to ensure standardized levels throughout the experiment using a precision thermocouple multimeter (Tenma, Springboro, $\mathrm{OH}$ ) and a LI-180 light meter (LI-COR, Inc., Lincoln, NE), respectively.

\section{Sampling methods}

Gross primary productivity (GPP), overall photochemical quantum yield (YIELD), and dark-adapted chlorophyll fluorescence $\left(F_{v} / F_{m}\right)$ were measured for each sample tube once a week for 5 weeks during the pre-treatment/acclimation period (Days $8,15,22,29$, and 36 ), and two times following the subzero treatment/ recovery period: 5 days after the freeze and 2 weeks after the freeze (Days 46 and 55). For those samples 
that underwent the freeze event (Day 40), measurements were also made at initiation and conclusion of the event at $6{ }^{\circ} \mathrm{C}$ (Days 39 and 41 ). Gross primary productivity was calculated by combining net primary productivity with respiration rates. Net photosynthesis was measured in a closed-system chamber whereby each sample tube was placed in a $1 \mathrm{~L}$ cuvette attached to a LI-6200 Portable Photosynthesis System (LI-COR, Inc., Lincoln, NE). Respiration rates were determined by taking a second measurement of each sample with a dark cloth over the cuvette. Both YIELD and $F_{v} / F_{m}$ of all samples were measured with an OS5-SP Fluorometer (OptiSciences, Inc. Tyngsboro, MA). Dark conditions needed for measurements were achieved by briefly turning chamber lights off. All pre/post-freeze measurements were taken at $18^{\circ} \mathrm{C}$, and moss was water saturated $<1$ $\mathrm{h}$ prior to all measurements.

Growth was evaluated through four components: biomass accumulation via net dry weight (NDW), net elongation of the main branch (NEMB), frequency of branching measured by summing the total number of new branches (NB), and the total new branch length per microcosm (NBL). All growth measurements were taken at the initiation of the experiment and 8 weeks later (Day 56), at its conclusion.

Treatment: freeze-thaw event

After all samples were watered, one sample out of the four growing in each light/temperature growing condition combination was subjected to an artificial freezethaw event. A second, independent freeze-event was performed on the other half of the experimental samples of the trial approximately three days after the first event. The 36hour, freeze-thaw event began after the completion of the fifth week of pretreatment 
measurements. Experimental sample tubes were placed in a cooler of ice, and the cooler was placed into a $6{ }^{\circ} \mathrm{C}$ chamber (EGC 15, Environmental Growth Chambers, Chagrin Falls, $\mathrm{OH})$. Each sample was equipped with a fine, 15 gauge copper constant thermocouple attached to a Campbell CR10X datalogger (Campbell Scientific, Login, UT). After $12 \mathrm{~h}$ at $6{ }^{\circ} \mathrm{C}$, physiological measurements were taken. After the samples were covered with Parafilm ${ }^{\circledR}$ (American National Can, Chicago, IL) to prevent water addition from the freezer or ice, the samples were placed at $0^{\circ} \mathrm{C}$ for $12 \mathrm{~h}$ by covering tubes with ice and placed in a $2{ }^{\circ} \mathrm{C}$ refrigerator for $12 \mathrm{~h}$. At this time, light levels were reduced to zero for control sample tubes with no change in temperature conditions to prevent a difference in total potential growing time between control and experimental plants. To continue the freezing process, samples were moved to a $-20^{\circ} \mathrm{C}$ freezer for $12 \mathrm{~h}$ where the temperature of the samples reached a low of $-12{ }^{\circ} \mathrm{C}$ (Figure 3). Because literature that estimates the lethal cold temperature for $S$. girgensohnii does not exist, the minimum temperature chosen was based on the lethal temperature of the least freeze resistant Sphagnum moss yet reported, S. magellanicum, which is $-16.6{ }^{\circ} \mathrm{C}$ (Balagurova et al. 1996). Temperature was maintained at all times at least $4{ }^{\circ} \mathrm{C}$ above this lethal temperature. All six FTE averaged $-5.04 \pm 0.13$, which is similar to the average temperature of FTEs that occurred at Toolik Lake, AK, on August $30,1988\left(-6.9^{\circ} \mathrm{C}\right)$; September 12, $1991\left(-5.2^{\circ} \mathrm{C}\right)$; September 1, 1993(-4.5 $\left.{ }^{\circ} \mathrm{C}\right)$; June 1, $1997\left(-4.2^{\circ} \mathrm{C}\right)$; May 28, $2002\left(-6.5^{\circ} \mathrm{C}\right)($ Shaver \& Laundre 2003.). After the $12 \mathrm{~h}$ subzero period, sample tubes were returned to control conditions in the reverse order of temperatures and at the same rate they were taken to reach the climax of the FTE. 


\section{Statistical methodology}

All data was analyzed using the statistical program SAS (SAS v 9.1, SAS Institute, Cary, NC). Prior to analysis, normality and heterogeneity of variances of all data were verified. Growth data were examined using a split-plot design to minimize any within chamber effects. Physiology data collected to compare light-temperature interactions prior to any freeze event were analyzed using a split-plot design with repeated measures. Lastly, a split-split plot design was utilized to examine the response of the freeze-thaw event. For the purposes of this study as a result of the small sample sizes, I consider $\mathrm{p}<0.1$ to be statistically significant.

\section{Results}

\section{Light-temperature growing environments}

Overall, light treatments exhibited a significant influence on the growth of the control samples: net dry weight $(p=0.0092)$, net elongation of main branch $(p=0.0240)$, number of new branches $(p=0.0848)$, new branch length $(p=0.0532)($ Table 1$)$. The number of new branches was found to vary strongly also among temperature environments $(p=0.0015)$, which lead to yielding a significantly different response among the light-temperature regimes $(p=0.0488)$ (Table 1). Over the 8-week experimental period, net dry weight (NDW) was greatest in the low light environments ( $p$ $=0.018)$ with the highest NDW found in the LLHT conditions $(x=0.215 \pm 0.122 \mathrm{~g}$, Figure 4a, Plate 4). The change in the main branch length or net elongation of main branch $(\mathrm{NEMB})$ was also greatest in low light conditions $(\mathrm{p}=0.024)$. Individuals from the LLLT environment had the largest mean length increase of $0.37 \pm 0.07 \mathrm{~cm}$ compared 
to the other three growing environments, where means ranged from $0.16 \pm 0.06$ (LLHT) to $0.22 \pm 0.07 \mathrm{~cm}$ (HLLT) (Figure $4 \mathrm{~b}$ ). New growth in the form of number of branches (NB) (Figure 4c) and length of those new branches (NBL) (Figure 4d) were largest in the LLHT growth environment with the mean number of new branches equaling $25.2 \pm 4.7$ and a mean total branch length per sample of $35.60 \pm 10.61 \mathrm{~cm}$ (Plate 5).

Weekly physiology measurements prior to freeze treatment revealed that gross primary productivity (GPP) was generally higher for samples grown in high-temperature environments regardless of light (Figure 5a). No difference in GPP was found within the first week, but values in the second week showed a significant increase for hightemperature samples over GPP of the low-temperature samples (Figure 5a), which produced a statistically significantly temporal difference between temperature regimes (Table 2). By week three however, all samples had established similar GPP rates with the highest GPP occurring in the low-light, high-temperature environment (Figure 5a). All treatments showed a reduction at week 5 prior to freeze treatment. Because samples were growing over the period, these values potentially reflect both changes in tissue photosynthetic capacity as well as changes in the amount of photosynthetic tissue.

The average photochemical quantum yield (YIELD) during the 5 week period pre-freeze treatment ranged from $0.446 \pm 0.011$ to $0.562 \pm 0.026$, and showed a similar trend as GPP with LLHT samples showing the highest YIELD values (Figure 5b). However differences in YIELD between light-temperature environments were not statistically significant (Table 2). Similar to the temporal GPP trend, low light levels produced higher YIELD during weeks 2 and 3 (Figure 5b), which accounts for the significant light*week variation (Table 2). 
Results of dark-adapted chlorophyll fluorescence $\left(\mathrm{F}_{\mathrm{v}} / \mathrm{F}_{\mathrm{m}}\right)$ exhibited the same tendency as GPP and YIELD during the five-week pre-freeze period, where samples had the highest mean $F_{v} / F_{m}$ in the LLHT environment $(x=0.652)$ and the lowest mean $F_{v} / F_{m}$ were from the HLLT environment $(x=0.585$, Figure $5 c)$. Throughout the pre-freeze period, the mean $F_{v} / F_{m}$ in the LLHT environment each week remained almost constant and consistently above the mean $\mathrm{F}_{\mathrm{v}} / \mathrm{F}_{\mathrm{m}}$ for other environments, with the exception of LLLT that peaked during week 3 (Figure 5c). Overall, the effects of temperature $(\mathrm{p}=$ $0.004)$ and the effects of light $(p=0.095)$ on $F_{v} / F_{m}$ differed during the growing period.

Changes in physiological activity of Sphagnum girgensohnii during freeze treatment Immediately prior to freezing, physiological measurements were taken on experimental samples of $S$. girgensohnii once their temperatures had attained $6^{\circ} \mathrm{C}$ for a minimum of $4 \mathrm{~h}$, and samples were measured again at the conclusion of the freeze after samples had readjusted to $6{ }^{\circ} \mathrm{C}$ for $4 \mathrm{~h}$. The $6^{\circ} \mathrm{C}$ conditions at the commencement of the freeze depressed GPP for experimental samples, down $36.2 \%$ from the same samples measured the previous day at $18^{\circ} \mathrm{C}$ (Figure 6a). Also affected by the initial $12^{\circ} \mathrm{C}$ decrease, YIELD was reduced by $24.2 \%$ (Figure $6 b$ ). However, $F_{v} / F_{m}$ was only slightly reduced, $8.9 \%$ (Figure $6 \mathrm{c}$ ).

Physiological measurements taken at $6{ }^{\circ} \mathrm{C}$ at the conclusion of the freeze event indicated a significant reduction in GPP for samples grown in all light-temperature environments $(\mathrm{p}<0.001)$ (Table 3). Overall, $S$. girgensohnii underwent a $44.3 \%$ average decrease in GPP from measurements taken at $6{ }^{\circ} \mathrm{C}$ over all FTE samples, with HLLT samples showing the greatest decrease on average, $49.1 \%$ (Figure 6a). The freeze reduce 
the YIELD of all plants $(\mathrm{p}=0.027)$, but the FTE impact was shown to have reduced the YIELD of LL regimes more $(p=0.092)$ (Table 3). Specifically, changes in YIELD differed among the treatments where LLHT plants decreased the most, falling by an average of $35.1 \%$ (Figure $6 \mathrm{~b}$ ). Samples from LLHT also exhibited a $15.1 \%$ decrease in $\mathrm{F}_{\mathrm{v}} / \mathrm{F}_{\mathrm{m}}$ ratio, but variations did not show significance. (Figure $6 \mathrm{c}$, Table 3 ).

Rate of physiological recovery from a freeze-thaw event

The freeze-thaw event caused an observable loss of chlorophyll in the newest tissue (Plate 6), suggesting that the FTE was particularly damaging to the photosynthetic apparatus of young tissue. Gross primary production of samples that underwent freezing remained depressed over the 2-week recovery period: Day 36 verse Day $46(p=0.021)$ (Table 4); Day 36 verse Day $55(\mathrm{p}<0.001$ ) (Table 5) (Figure 7a). At the conclusion of the 8-week growth period (Day 55), control samples all showed greater GPP when compared to their GPP during week 5. Plants grown under high temperature that underwent a FTE also showed an increase in GPP when compared to GPP measurements collected week 5, however, those increases were small in comparison to the increased GPP of control samples grown in the high temperature treatments. The GPP of low temperature treatment plants was reduced after the FTE compared to levels measured prior to the FTE, as well as in comparison to GPP of low temperature controls measured during week 8. In response to a FTE, GPP of samples in HLLT environments declined by $28.1 \%$ and those in LLLT declined $22.7 \%$ compared to values from week 5 . Compared to control samples at week 8, the percent reduction in GPP due to the FTE was even larger: HLHT (13.3\%); HLLT (34.2\%); LLHT (44.4\%); LLLT (50.2\%). A GPP comparison of 
the difference between Day $36 \& 46$ and Day $36 \& 55$ reveal a slight significant variation with Day 55 reflecting small physiological changes during this recovery period. (Table 6, Figure 7a).

During the two weeks following the freeze, changes in YIELD values from before the freeze to after in both control and freeze-treated samples were minimal (Figure 7b). However, a comparison of YIELD changes between Day 36 and Day 46 shows a significant difference between frozen and control plants $(p=0.021)$. Those plants growing in HT environments actually displayed a small increase in YIELD six days into the recovery period. Fourteen days post-freeze, slight reductions in YIELD were found in the samples grown in LLHT (9.1\%) and LLLT (6.0\%) conditions when compared to control samples. However, collection of fluorescence data for both YIELD and $F_{v} / F_{m}$ became more difficult in FTE samples for which no appreciable $\mathrm{F}_{0}$ signal was found in initial measurements, and often multiple attempts were necessary to obtain any reading.

Likewise, differences observed in $F_{v} / F_{m}$ from before the freeze compared to after the freeze in both control and FTE samples were significant six days after the FTE with frozen samples having an increased $F_{v} / F_{m}$ when recovering in a HT environment (Table 4, Figure $7 \mathrm{c})$. Values of $F_{\mathrm{v}} / \mathrm{F}_{\mathrm{m}}$ taken 14 days after the freeze indicate that differences between FTE and control plants may have disappeared during this recovery period. (Table 5, Table 6, Figure 7c).

Growth impacted from a freeze-thaw event

Growth in all four categories was reduced from exposure to a FTE: NDW (p = 0.015); NEMB ( $=0.035) ; \mathrm{NB}(\mathrm{p}=0.009) ; \mathrm{NBL}(\mathrm{p}<0.001)$ (Table 7, Figure 8a). The 
freeze-thaw event caused an observable loss of chlorophyll in the newest tissue (Plate 6). Dry weight accumulation measurements (NDW) taken after the recovery period revealed that the samples grown under low light treatments were quantitatively more negatively impacted by the FTE than those grown in high light environments (Figure 8a). The traditional field assessment for Sphagnum growth, NEMB, lacked any interaction between light environments and the response to the freeze-thaw event. In contrast, the main effect of temperature was significant for NEMB in response to the FTE; plants grown in the colder treatments fared the worst $(p=0.007)$.

Without encountering a FTE, the number of new branches of Sphagnum (NB) and the length of those branches (NBL) were significantly higher in HT environments than LT ones $(p=0.042, p=0.057$, respectively) (Table 8$)$. However, this advantageous growth found in HT environments was lost after the FTE (Table 8). Comparing each light-temperature environment against one another, three cases of such a loss in growth, which was produced in more ideal pre-freeze conditions, were observed (Table 9). The shading advantage plants gained to produce a significantly high number of branches (NB) and new branch length (NBL) in LLHT environment over the HLHT environment was lost (Table 9). Likewise, shading no longer posed as an advantage to when comparing those plants that grew at low temperatures; the main branch (MBEL) of LLLT plants were significant longer than HLLT plants when no FTE was encountered $(p=0.021)$, but the difference was not significant in those samples which experienced a FTE $(p=0.279)$ (Table 9.) The remaining instances of growth occurring in one light-temperature environment being not significantly different from that of another environment before 
FTE and then shifting to an insignificant variation or vice versa is most likely due to the large standard error among the samples growing the better performing environments.

\section{Discussion}

Preference for a low light-high temperature environment

Sphagnum girgensohnii grown in LLHT condition had the greatest overall growth including NDW, NB and NBL and productivity in terms of GPP, YIELD and $F_{v} / F_{m}$. Low light conditions in this experiment simulate partially shaded in situ environments, which have been found to encourage Sphagnum growth and productivity. Foremost, partial shading has been argued to be a requirement for the peat mat formation. The ability of Sphagnum individuals to grow as uniform mats has been attributed to individual ramets increasing growth rates upon shading by nearest Sphagnum neighbors, often referred to as self shading (Malmer et al. 1994).

The average photochemical quantum yield (YIELD) over the 5 week pre-freeze treatment showed Sphagnum in low light environments performing better. Visual comparison of $\mathrm{HL}$ and LL samples showed the latter having transition from an in situ brown color to predominantly green suggesting as the YIELD has that the quantity of chlorophyll increased under the low light environment to a measurable level in only a few weeks.

Higher solar irradiance in situ has been suggested to result in photoinhibition in the genus Sphagnum (Murray et al. 1989). In environmental growth chamber experiment, Murray et al. (1993) found that high light $\left(800 \mu \mathrm{mol}\right.$ photons $\left.\mathrm{m}^{-2} \mathrm{~s}^{-1}\right)$ caused 
photoinhibition of photosynthesis. Although our high light treatment was almost $50 \%$ less than this known photoinhibitory level, $S$. girgensohnii grown under our higher chamber light ( 450 umol photons $\mathrm{m}^{-2} \mathrm{~s}^{-1}$ ) may have been experiencing partial light saturation at the time physiological measurements were taken for all samples at high light conditions.

Low light resulting in shading of vascular plants has also been seen to increase growth in Sphagnum, as in the process of etiolation. Furthermore, low light conditions caused by vascular plants have been show to reduce evapotranspiration allowing Sphagnum to retain water and soluble nutrients within and upon the hyaline cells (Plate 7) that is crucial to productivity (Heijmans et al. 2001). Lower evapotranspiration rates were likely an important contributing factor to the high growth and productivity of LL plants as a result of shading, despite daily water saturation of all samples.

\section{Warmer climate preference}

Statistically, low light environments produced $S$. girenesohnii that had higher rates of NEMB, which points to etiolation. However, the LLLT environment was responsible for the difference in NEMB rates between low and high light environments (Figure 4B). Under LLLT conditions, mosses shifted from growing via new shoots towards main stem elongation, suggesting that temperature may cue a change in hormonal control of growth. Field methodology that uses stem elongation only to evaluate growth, such as the crank-wire method (Roy et al. 2000), would potentially allow this temperature driven growth shift to go undetected. However, it is unclear from my results whether differences in NDW can solely be attributed to stem elongation 
(NEMB) and/or branching (NB \& NBL) or if changes in leaf morphology and leaf mass may be contributing to NDW. The ecological implications of such a shift in growth form in response to temperature is that the spread of peat mats via new shoot regeneration is more difficult at lower temperatures, and thus, potentially at higher elevations, where it is typically colder during the growing season. This conclusion is circumstantially supported by the decreased prevalence of Sphagnum from boreal to high arctic regions.

\section{Regeneration via branching}

Unexpectedly, all simulated growing conditions resulted in branching, complete with capitula, at a higher rate than observed in the field. This finding may be a result of chamber conditions differing in some unique way from ideal growing conditions. Clymo \& Duckett (1986) argue that innovations responsible for branching typically remain dormant in the top few centimeters of green Sphagnum due to some apical dominance mechanism, which conflicts with these findings. The storage time between in situ harvest and initiation of the experiments caused the capitula of most plants to lose greenness. Although Sphagnum plants that branched had green capitula at the time of harvest, their stressed state at the start of the experiment, as indicated by homogenous brownness, may have released any apical dominance. Such a regeneration alternative might indicate that branching can occur following a winter when chlorophyll is in lower concentrations in capitula compared to the peak of a growing season.

Alternatively, the high rate of branching in our findings may be in response to greater light availability below the capitula in my microcosm compared to that found within mats in situ, irrespective of any change in apical dominance. Such a branching 
response to decreased shading of moss stems could serve as a recovery mechanism of a disturbed mat.

Investigations examining above and below biomass growth often occur late in the arctic growing season. This method may preclude detection of below surface branching in Sphagnum because one or more freeze event(s) may have occurred during the season, which could eliminate any young, tender offshoots. Harvesting of materials to transport for this growth chamber experiment in summer 2002 took place after two strong summer snowstorms and freeze thaw events. Some minimal branching was observed and removed as the natural mats were disassembled for preparation for this experiment. More branching may have occurred and then died back within the season prior to harvest.

\section{Changes in physiological activity in Sphagnum during a freeze-thaw event}

Reduction in temperature to $6{ }^{\circ} \mathrm{C}$ at the beginning of the FTE correlated with lower physiological activity, as expected. Low GPP at this reduced temperature indicated that Sphagnum is highly sensitive to temperature changes. As indicated by YIELD, the efficiency of photosynthetic electron transfer declined quickly, although the quantum yield indicated by $F_{v} / F_{m}$ remained high.

The reduced GPP collected at the end of the FTE at $6{ }^{\circ} \mathrm{C}$ showed that plants from all light-temperature environments were impacted, and at the time of post FTE measurements, partial intracellular and intercellular freezing may have still persisted, contributing to depressed physiological activity. With the greatest reduction in GPP, $S$. girgensohnii grown in HLLT also had the highest number of tender new branches except for LLHT plants (Figure 4c). Given the small size of new branches in the HLLT category 
(Figure 4d), they may have been too young to survive the FTE and their subsurface destruction may be the source of the substantial loss of GPP immediately following the FTE.

In the LLHT environment, where plants grew best, both YIELD and $F_{v} / F_{m}$ ratio declined strongly in response to the FTE. Even if the FTE caused substantial shoot damage, the large volume of moss below the surface in these samples may have been able to mask the damage in terms of GPP. Fluorescence measurements indicate that at least on the surface the LLHT moss lost some photosynthetic capability and exhibited stress following the FTE.

Sphagnum growth at low-temperature: physiologically vulnerable to freeze-thaw events After the FTE, Sphagnum samples under all treatments displayed reduced GPP that remained low until the conclusion of the experiment. Those plants that had not undergone a FTE showed increased GPP over values taken before FTE, indicating that nutrient limitation or a decline in the quality of the growing environment did not account for the decrease in GPP found in the FTE treated samples. High temperature environments, regardless of light levels, produced samples with higher GPP after the FTE than before, but still lower than their control counterparts. High temperatures may have promoted increased vegetative biomass so that sufficient sample remained physiologically intact following the FTE to respond positively during the recovery period. However, samples growing well prior to the FTE may show a large effect from the FTE, as seen by comparing the treatment effect to measurements taken prior to the FTE (Figure 8). 
Although not statistically shown, freeze-treated Sphagnum grown at low temperature seemed to display a deteriorated state after freezing. The cool temperatures following the FTE may have prolonged the negative effects of FTE whereby intracellular and intercellular freezing may have continued for a more extended period and exposure to growth light conditions during the longer thawing period may have caused photosynthetic damage (Murray et al. 1993). This suggestion is supported by the finding of lower $F_{v} / F_{m}$, a sensitive measure of stress, only for low temperature samples. Furthermore, following thawing low temperatures may have limited photosynthetic activity and thereby the ability of the plants to repair photosynthetic damage.

Freeze-thaw event: modes of growth and growing conditions yield differing responses The effect of a FTE on the four different measurements of Sphagnum growth add further evidence that the environment may trigger Sphagnum plants to shift from elongation to branching or vice versa. Examination of NDW changes alone do not reveal this process, however, but does support my hypothesis that Sphagnum grown in a favorable growing environment, such as the low light environment, incurs more damage from a FTE. Losing the least NDW from the FTE, Sphagnum from the HLLT may have had the least photosynthetic damage as a result of low growth and photosynthetic activity in the five weeks prior to the FTE, as indicated by the GPP data. Exposure to the stress of high light may have preconditioned the plants for the stress of freezing and thawing. Such a characteristic would be especially advantageous for Sphagnum species during early spring, as it would ensure quick recover from fluctuating temperatures at the beginning of the growing season. Once temperatures warmed, the density of capitula 
could quickly return filling out the tundra mat. However, due to the severity of this experiement FTE, this cannot be verified, since different light-temperature regimes seemed to do little in preparing the most vunenable new shoots.

Sphagnum individuals grown under low temperature were found to have lost more of their NEMB growth from the FTE. Phenological and physiological damage from naturally occurring FTE have been observed for arctic vascular plants (Gorsuch \& Oberbauer 2002). However, damage to Sphagnum mosses and changes in mat heights have been more difficult to observe, given the naturally occurring changes in hydrology during a FTE and the limitations in measuring Sphagnum growth. I believe that these are the first data that indicate that Sphagnum growing in the cold tundra may be negatively impacted by severe FTE, including loss of main stem elongation that halts further mat advancement. Thus, FTEs may not give Sphagnum species any advantage over vascular plants as all plants, vascular and nonvascular species alike, need a recovery period from such an event.

Although the range of measured NEMB may appear small $(0.07-0.37 \mathrm{~cm})$, it is comparable to field observations of growth over an 8-week period, but with much better precision. The crank-wire method is typically used to measure NEMB of Sphagnum where it is challenging to measure to better than $0.3 \mathrm{~cm}$. In the laboratory, measurements were collected with more precision $(0.1 \mathrm{~cm})$ and accuracy due to the dissection of the mat.

Damage due to the FTE was most visible when growth was evaluated via NB and NBL. Such a response shows that Sphagnum grown in any environment containing an occasional FTE may lose branch growth. Therefore FTE may operate as a factor affecting 
Sphagnum growth and the occurrence of FTE may be positively correlated to Sphagnum mat advancement. Sphagnum grown in low temperatures yielded damage to both NB and NBL, allocating future growth to elongation. Furthermore, LLHT plants displayed some loss of new branches and new branch length after a FTE, and this research revealed that a severe FTE may cause Sphagnum to lose any advantages a warmer, shadier environment may have offer. During the recovery period, LLHT may have responded to this loss in branches by allocating surviving resources to grow to main stem elongation. Hence, the 2 week recovery period may be responsible for producing LLHT individuals with longer main branches than plants grown in the LLHT continuously for 8 weeks without any damaging FTE. If this is the case, a warmer, shadier environment in the Arctic with the occasional FTE, may push Sphagnum to continue to grow primarily via their main branches, thereby continuing mat advancement and potentially influencing the vascular community.

\section{Warmer Climate: Sphagnum Loses Ecosystem Engineering Ability}

Sphagnum has been classified as a potential ecosystem engineer, modifying the environment for its own persistence (Svensson 1995, Van Breemen 1995). When grown with Sphagnum, vascular plants allocate primarily to vertical growth to prevent engulfment by the upwardly advancing Sphagnum mat (Malmer et al. 1994). Prior to my findings, Sphagnum was assumed to chiefly utilize one mode of growth typically measured with the crank-wire method. Interactions between abiotic factors, vascular plant growth, and the growth strategy of Sphagnum have yet to be described. In Figure 9, I present a model that summarizes these interactions. 
A cold Arctic with cool summers preserves Sphagnum and its engineering role in the ecosystem. With minimal vascular vegetation in an environment of HLLT, Sphagnum grows slowly with minimal branching causing an advancing mat, which results in vertical vascular growth (Svennson 1995). This pressure coupled with cold temperatures and a short growing season results in vascular plant growth allocated to height but not density for shrubs such as Betula and Salix, thereby maintaining a high light environment for Sphagnum species. In environments with more favorable conditions such as increased nutrient availability, shrub leaf density may increase in addition to vertical growth, decreasing the light environment for Sphagnum below. Such a shift may be short term, however, because the growth strategies of Sphagnum may act as a negative feedback. The colder, lower light environment in this experiment triggered increased elongation, and therefore a quick increase in mat height, which results in an increased need for vertical vascular plant growth. With resources allocated to vertical growth, vegetative cover is minimized and higher light conditions are returned for the Sphagnum understory.

Under warming climate conditions, the stability of this peat-dominated system may erode. A warmer, high light environment, such as HLHT condition in this experiment, would increase Sphagnum growth through elongation and some branching. Growth would probably be modest as it was in our experiment. Many vascular species are expected to positively respond to increases in summer temperatures and longer growing seasons via earlier snowmelt (Walker et al. 2006). As the Sphagnum mat advances and vascular competition for nutrient availability increases, small evergreen and forb species may be initially negatively affected. Deciduous shrubs such as Salix and Betula species could increase in both height and leaf density, resulting in a potential 
stable and preferred low light environment for the Sphagnum below. Our data showed that the LLHT environment resulted in high growth largely attributed to a high level of below surface branching. With Sphagnum allocating growth to branching and less to elongation, the Sphagnum mat may slow its advance and thereby (1) halt any negative impact it may have on small evergreens and forbs and (2) remove pressure on deciduous shrubs to grow vertically, which allows vascular cover to maintain a low light environment for Sphagnum.

\section{Sphagnum and permafrost}

Under warming microclimate conditions in the Arctic, woody shrubs such as Betula and Salix species positively respond with increase vegetative cover (Kullman 2002), which would produce a favorable lower light environment for S. girgensohnii, a species commonly found in almost full light throughout the Brooks Range, Alaska. The preferred low light coupled with warmer temperatures may increase nonvascular growth, thereby mitigating active layer expansion with the nonvascular mat's insulating characteristics. In a multi-dimensional dynamic climate, however, Sphagnum may support the growth of woody shrubs to its own detriment due to shifts in the allocation of growth. Low light with higher temperature resulted in increased growth via branching that collectively increases mat density, perhaps a short-term mechanism against belowground temperature increase and indirect vascular competition. Such a mechanism may mitigate permafrost decline for an occasional warmer arctic growing season, but coupled with a warming trend, may destabilize the permafrost and existing plant community over a series of consecutive warmer seasons for several reasons. 
(1) A denser mat may serve to isolate atmospheric temperatures from the upper areas of permafrost over a season, but the lack of vertical Sphagnum growth over many years may allow collective warming belowground as the distance between permafrost and atmosphere is reduced. Heat could be transferred across this distance via extracellular water found on Sphagnum species.

(2) An increase in mat density allows the retention of extracellular water by reducing evapotransipartion. Waddington et al. (2001) found that higher temperature and soil moisture resulted in increased production rates in peat. This acting alone would facilitate further growth Sphagnum and insulating below. However, with permafrost levels already falling in warmer microclimates (Jorgenson et al. 2006), dropping water tables are expected to follow (Woo \& Young 2006). In fens primarily, water retained initially in the dense Sphagnum mats may be lost to the competing vascular plants, giving them a successional advantage.

(3) A denser Sphagnum mat may be more hospitable for germination of some vascular seedlings. Many tightly woven Sphagnum individuals could serve to supply a vascular seed with amply water and nutrients and cradle it closer to the surface than a typical mat. If such parameters are improved for a particular vascular form, then it may have a short-term competitive advantage over the rest of the plant community.

(4) Vascular plants grown with Sphagnum have exhibited pressure to produce vertical growth. Changes in mat density may change the competition that occurs within the vascular community. 
Freeze-thaw events as an ecosystem influence

Freeze-thaw events interrupt the growth and physiology of Sphagnum. Sphagnum growing in optimal growing climates may be more likely to be affected by such events, not because of their overall lack of cold temperature acclimation, but rather because of greater loss of new biomass. Continuous loss of new tissue due to frequent FTE may reduce the likelihood of branching, which may influence mat regeneration, an important issue in restoration of northern bog ecosystems.

The lack of FTE in a warmer climate may result in a stalling of Sphagnum mat advancement as a result of increased branching. Such a combination of a continuously warmer growing season without periodic "cold snaps" may reduce the competitive pressure for vascular plants to grow vertically. In contrast, the presence of FTE in a warmer Arctic may provide a mechanism in which Sphagnum species continue to grow vertically because the occasional FTE damage tender new branches. Thus the advancement of the Sphagnum mat may continue under a warmer climate given the occurrence of FTEs. 
Table 1. Analysis of variance of growth response to light and temperature: net dry weight (NDW); net elongation of main branch (NEMB); total number of new branches per sample (NB); total new branch net elongation per sample (NBL). D.F. $=1$. Bolded values are statistically significant at $\mathrm{p}<0.10$. Plants never incurred a FTE.

\begin{tabular}{cccccccccc}
\hline & \multicolumn{2}{c}{ NDW } & \multicolumn{2}{c}{ NEMB } & \multicolumn{2}{c}{ NB } & \multicolumn{2}{c}{ NBL } \\
\hline Source of & & & & & & & & \\
Variation & $\mathrm{F}$ & $\mathrm{p}$ & $\mathrm{F}$ & $\mathrm{p}$ & $\mathrm{F}$ & $\mathrm{p}$ & $\mathrm{F}$ & $\mathrm{P}$ \\
\hline Light & 7.52 & $\mathbf{0 . 0 0 9}$ & 5.73 & $\mathbf{0 . 0 2 4}$ & 3.13 & $\mathbf{0 . 0 8 5}$ & 4.04 & $\mathbf{0 . 0 5 3}$ \\
Temperature & 0.32 & 0.577 & 0.17 & 0.696 & 12.97 & $\mathbf{0 . 0 0 2}$ & 9.55 & $\mathbf{0 . 0 2 7}$ \\
Light*Temp & 0.08 & 0.777 & 2.08 & 0.161 & 4.14 & $\mathbf{0 . 0 4 9}$ & 2.10 & 0.157 \\
\hline
\end{tabular}

Table 2. Analysis of variance of physiological response to light and temperature during 5 weeks of growth: gross primary productivity (GPP); overall photochemical quantum yield (YIELD); dark-adapted chlorophyll fluorescence (Fv/Fm).

GPP

YIELD

$\mathrm{Fv} / \mathrm{Fm}$

\begin{tabular}{ccccccc}
\hline $\begin{array}{l}\text { Source of } \\
\text { Variation }\end{array}$ & $\mathrm{F}$ & $\mathrm{P}$ & $\mathrm{F}$ & $\mathrm{p}$ & $\mathrm{F}$ & $\mathrm{p}$ \\
\hline Light & 2.61 & 0.152 & 7.08 & 0.113 & 8.38 & $\mathbf{0 . 0 0 6}$ \\
Temperature & 4.03 & 0.130 & 1.69 & 0.260 & 2.19 & 0.214 \\
Light*Temp & 0.46 & 0.520 & 0.11 & 0.737 & 0.49 & 0.485 \\
Light*Week & 1.49 & 0.222 & 3.48 & $\mathbf{0 . 0 1 5}$ & 2.12 & $\mathbf{0 . 0 9 5}$ \\
Temp*Week & 6.97 & $<\mathbf{0 . 0 0 1}$ & 1.91 & 0.126 & 4.47 & $\mathbf{0 . 0 0 4}$ \\
Light*Temp* & 1.47 & 0.244 & 0.31 & 0.9015 & 0.30 & 0.907 \\
Week & & & & & &
\end{tabular}


Table 3. Analysis of variance of physiological response between Day 39 and Day 41 under light, temperature and FTE differences measured at $6^{\circ} \mathrm{C}$ : gross primary productivity (GPP); overall photochemical quantum yield (YIELD); dark-adapted chlorophyll fluorescence $\left(\mathrm{F}_{\mathrm{v}} / \mathrm{F}_{\mathrm{m}}\right)$. FTE occurred on Day 40.

GPP YIELD $\quad \mathrm{F}_{\mathrm{v}} / \mathrm{F}_{\mathrm{m}}$

\begin{tabular}{ccccccc}
\cline { 1 - 4 } $\begin{array}{c}\text { Source of } \\
\text { Variation }\end{array}$ & F & P & F & P & F & p \\
& & & & & & \\
Light & 0.30 & 0.582 & 0.00 & 0.973 & 0.38 & 0.546 \\
Temperature & 0.02 & 0.904 & 0.61 & 0.473 & 0.01 & 0.938 \\
Freeze & 41.01 & $<\mathbf{0 . 0 0 1}$ & 5.71 & $\mathbf{0 . 0 2 7}$ & 0.93 & 0.347 \\
Light*Temp & 0.00 & 0.953 & 0.45 & 0.510 & 0.03 & 0.862 \\
Light*Freeze & 0.08 & 0.778 & 3.14 & $\mathbf{0 . 0 9 2}$ & 2.07 & 0.166 \\
Temp*Freeze & 0.01 & 0.931 & 0.47 & 0.499 & 0.72 & 0.408 \\
Light*Temp & 0.04 & 0.956 & 0.24 & 0.786 & 0.08 & 0.924 \\
*Freeze & & & & & & \\
\hline
\end{tabular}

Table 4. Analysis of variance of physiological difference between Day 36 and Day 46: gross primary productivity (GPP); overall photochemical quantum yield (YIELD); darkadapted chlorophyll fluorescence $\left(F_{v} / F_{m}\right)$. FTE occurred on Day 40 .

$\begin{array}{lll}\text { GPP } & \text { YIELD } & \text { Fv/Fm }\end{array}$

\begin{tabular}{lccccccc}
\cline { 5 - 7 } $\begin{array}{l}\text { Source of } \\
\text { Variation }\end{array}$ & & & & & & \\
& & $\mathrm{p}$ & $\mathrm{F}$ & $\mathrm{P}$ & $\mathrm{F}$ & $\mathrm{p}$ \\
\cline { 5 - 8 } & & & & & & \\
Light & 0.61 & 0.440 & 5.03 & $\mathbf{0 . 0 3 1}$ & 3.35 & $\mathbf{0 . 0 9 7}$ \\
Temperature & 0.56 & 0.532 & 0.72 & 0.484 & 0.03 & 0.877 \\
$\quad$ Freeze & 5.84 & $\mathbf{0 . 0 2 1}$ & 3.25 & $\mathbf{0 . 0 8 0}$ & 12.95 & $\mathbf{0 . 0 0 5}$ \\
Light*Temp & 0.25 & 0.617 & 0.33 & 0.570 & 0.01 & 0.920 \\
Light*Freeze & 0.07 & 0.788 & 0.36 & 0.550 & 2.19 & 0.169 \\
Temp*Freeze & 0.05 & 0.827 & 0.21 & 0.653 & 6.15 & $\mathbf{0 . 0 3 2}$ \\
Light*Temp & 0.19 & 0.666 & 0.67 & 0.418 & 13.56 & $\mathbf{0 . 0 0 4}$ \\
*Freeze & & & & & &
\end{tabular}


Table 5. Analysis of variance of physiological difference between Day 36 and Day 55: gross primary productivity (GPP); overall photochemical quantum yield (YIELD); darkadapted chlorophyll fluorescence $\left(\mathrm{F}_{\mathrm{v}} / \mathrm{F}_{\mathrm{m}}\right)$. FTE occurred on Day 40 .

GPP YIELD $\quad$ Fv/Fm

\begin{tabular}{ccccccc}
\hline $\begin{array}{c}\text { Source of } \\
\text { Variation }\end{array}$ & $\mathrm{F}$ & $\mathrm{p}$ & $\mathrm{F}$ & $\mathrm{p}$ & $\mathrm{F}$ & $\mathrm{p}$ \\
\hline Light & 1.83 & 0.185 & 0.10 & 0.757 & 0.14 & 0.710 \\
Temperature & 0.04 & 0.866 & 0.03 & 0.876 & 0.03 & 0.874 \\
Freeze & 14.58 & $>\mathbf{0 . 0 0 1}$ & 0.04 & 0.851 & 0.27 & 0.605 \\
Light*Temp & 0.13 & 0.716 & 0.41 & 0.524 & 0.08 & 0.775 \\
Light*Freeze & 1.41 & 0.242 & 0.04 & 0.836 & 0.00 & 0.950 \\
Temp*Freeze & 0.07 & 0.794 & 0.00 & 0.996 & 0.00 & 0.978 \\
Light*Temp & 0.57 & 0.454 & 0.09 & 0.761 & 0.25 & 0.623 \\
*Freeze & & & & & & \\
\hline
\end{tabular}

Table 6. Analysis of variance of physiological difference between Day 46 and Day 55: gross primary productivity (GPP); overall photochemical quantum yield (YIELD); darkadapted chlorophyll fluorescence $\left(\mathrm{F}_{\mathrm{v}} / \mathrm{F}_{\mathrm{m}}\right)$. FTE occurred on Day 40.

$\begin{array}{lll}\text { GPP } & \text { YIELD } & \text { Fv/Fm }\end{array}$

\begin{tabular}{ccccccc}
\hline $\begin{array}{c}\text { Source of } \\
\text { Variation }\end{array}$ & $\mathrm{F}$ & $\mathrm{p}$ & $\mathrm{F}$ & $\mathrm{p}$ & $\mathrm{F}$ & $\mathrm{p}$ \\
\hline Light & 0.23 & 0.634 & 0.28 & 0.603 & 2.65 & 0.120 \\
Temperature & 0.01 & 0.915 & 3.41 & 0.206 & 0.01 & 0.943 \\
Freeze & 2.56 & 0.100 & 0.93 & 0.341 & 1.17 & 0.292 \\
Light*Temp & 0.21 & 0.647 & 0.06 & 0.802 & 1.49 & 0.238 \\
Light*Freeze & 0.04 & 0.965 & 0.00 & 0.979 & 0.06 & 0.810 \\
Temp*Freeze & 0.96 & 0.392 & 0.93 & 0.342 & 1.72 & 0.205 \\
Light*Temp & 0.30 & 0.825 & 0.17 & 0.680 & 0.23 & 0.634 \\
*Freeze & & & & & &
\end{tabular}


Table 7. Analysis of variance of growth response to a freeze-thaw event and interactions with light and temperature: net dry weight (NDW); net elongation of main branch (NEMB); total number of new branches per sample (NB); total new branch net elongation per sample (NBL).

\begin{tabular}{cccccccccc}
\hline & \multicolumn{2}{c}{ NDW } & \multicolumn{2}{c}{ NEMB } & \multicolumn{2}{c}{ NB } & \multicolumn{2}{c}{ NBL } \\
\hline $\begin{array}{c}\text { Source of } \\
\text { Variation }\end{array}$ & $\mathrm{F}$ & $\mathrm{p}$ & $\mathrm{F}$ & $\mathrm{p}$ & $\mathrm{F}$ & $\mathrm{p}$ & $\mathrm{F}$ & $\mathrm{p}$ \\
\hline Freeze & 6.54 & $\mathbf{0 . 0 1 5}$ & 4.78 & $\mathbf{0 . 0 3 5}$ & 7.60 & $\mathbf{0 . 0 0 9}$ & 17.81 & $<\mathbf{0 . 0 0 1}$ \\
Light*Freeze & 1.16 & 0.288 & 0.03 & $\mathbf{0 . 8 7 3}$ & 0.43 & 0.514 & 1.42 & 0.243 \\
Temp*Freeze & 0.28 & 0.599 & 8.31 & $\mathbf{0 . 0 0 7}$ & 0.86 & 0.359 & 0.04 & 0.858 \\
Light*Temp & 0.02 & 0.891 & 1.32 & 0.258 & 1.37 & 0.250 & 1.76 & 0.154 \\
*Freeze & & & & & & & & \\
\hline
\end{tabular}

Table 8. Analysis of variance- Difference of least squares means of growth response comparison among light and temperature environments with and without a FTE: net dry weight (NDW); net elongation of main branch (NEMB); total number of new branches per sample (NB); total new branch net elongation per sample (NBL). Comparisons of light-temperature environments that display a departure in significance due to a FTE are underlined.

\begin{tabular}{|c|c|c|c|c|c|c|c|c|}
\hline & \multicolumn{2}{|c|}{ NDW } & \multicolumn{2}{|c|}{ NEMB } & \multicolumn{2}{|c|}{ NB } & \multicolumn{2}{|c|}{ NBL } \\
\hline FTE & $\mathrm{N}$ & $\mathrm{Y}$ & $\mathrm{N}$ & $\mathrm{Y}$ & $\mathrm{N}$ & $\mathrm{Y}$ & $\mathrm{N}$ & $\mathrm{Y}$ \\
\hline $\begin{array}{c}\text { Growing } \\
\text { Environments }\end{array}$ & $\mathrm{p}$ & $\mathrm{p}$ & $\mathrm{p}$ & $\mathrm{p}$ & $\mathrm{p}$ & $\mathrm{p}$ & $\mathrm{p}$ & $\mathrm{p}$ \\
\hline HL vs LL & 0.6699 & 0.3375 & 0.3799 & 0.2829 & 0.3328 & 0.2510 & 0.1380 & 0.1885 \\
\hline HT vs LT & 0.0184 & 0.0111 & 0.1115 & 0.1348 & $\underline{0.0420}$ & $\underline{0.3664}$ & $\underline{0.0570}$ & $\underline{0.2941}$ \\
\hline
\end{tabular}


Table 9. Analysis of variance- Difference of least squares means of growth response comparison between light-temperature environments with and without a FTE: net dry weight (NDW); net elongation of main branch (NEMB); total number of new branches per sample (NB); total new branch net elongation per sample (NBL). Comparisons of light-temperature environments that display a departure in significance due to a FTE are underlined.

\begin{tabular}{cccccccccc}
\hline & \multicolumn{2}{c}{ NDW } & \multicolumn{2}{c}{ NEMB } & \multicolumn{2}{c}{ NB } & \multicolumn{2}{c}{ NBL } \\
\hline FTE & $\mathrm{N}$ & $\mathrm{Y}$ & $\mathrm{N}$ & $\mathrm{Y}$ & $\mathrm{N}$ & $\mathrm{Y}$ & $\mathrm{N}$ & $\mathrm{Y}$ \\
\hline $\begin{array}{c}\text { Growing } \\
\text { Environments }\end{array}$ & $\mathrm{p}$ & $\mathrm{p}$ & $\mathrm{p}$ & $\mathrm{p}$ & $\mathrm{p}$ & $\mathrm{p}$ & $\mathrm{p}$ & $\mathrm{P}$ \\
\hline HLHT vs HLLT & 0.2219 & 0.6691 & 0.7474 & 0.3647 & 0.6471 & 0.3764 & 0.6721 & 0.3124 \\
HLHT vs LLHT & $\underline{0.4022}$ & $\underline{0.0158}$ & 0.8575 & 0.2846 & $\underline{0.0023}$ & $\underline{0.2567}$ & $\underline{0.0124}$ & $\underline{0.2133}$ \\
HLHT vs LLLT & 0.1748 & 0.6043 & 0.2066 & 0.9340 & 0.8980 & 0.4117 & 0.7200 & 0.3755 \\
HLLT vs LLHT & 0.0628 & 0.0461 & $\underline{0.6922}$ & $\underline{0.0759}$ & $\underline{0.0809}$ & $\underline{0.1676}$ & $\underline{0.0273}$ & $\underline{0.1068}$ \\
HLLT vs LLLT & $\underline{0.0105}$ & $\underline{0.1935}$ & $\underline{0.0208}$ & $\underline{0.2791}$ & 0.6269 & 0.8917 & 0.9332 & 0.8152 \\
LLHT vs LLLT & 0.5771 & 0.1972 & 0.1867 & 0.3708 & $\underline{0.0489}$ & $\underline{0.1848}$ & $\underline{0.0303}$ & $\underline{0.1306}$
\end{tabular}


Figure 1. Experiment design. Shade samples of each 10-12 plants are represented by $\mathbf{L}$ where as non-shaded, high light samples are represented by $\mathbf{H}$. This trial was repeated a total of 6 times.

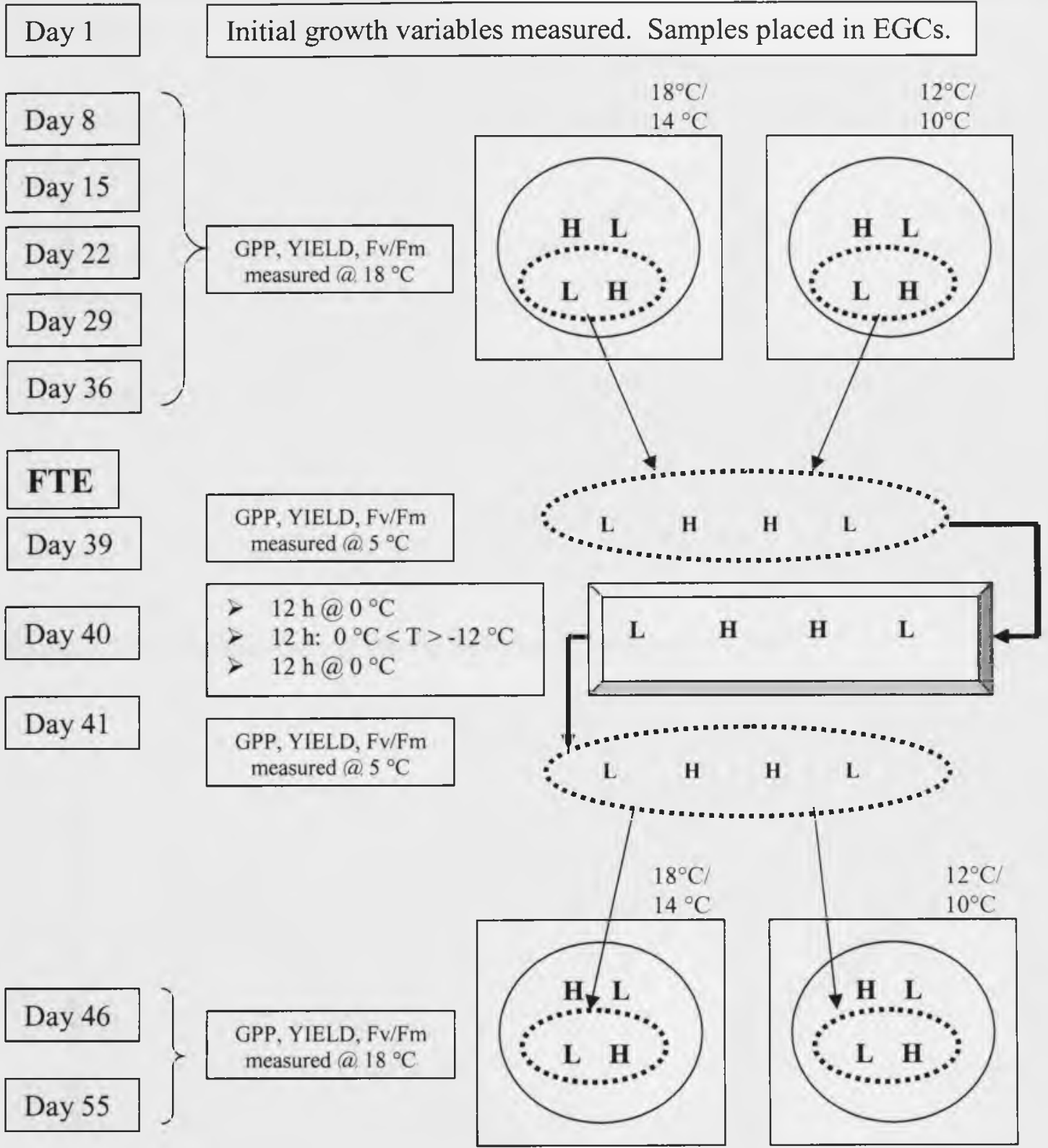

\section{Harvest}

Day 56

Samples harvested and final growth variables measured. 
Figure 2. Regression of water content method using dummy samples. $\mathrm{n}=32$.

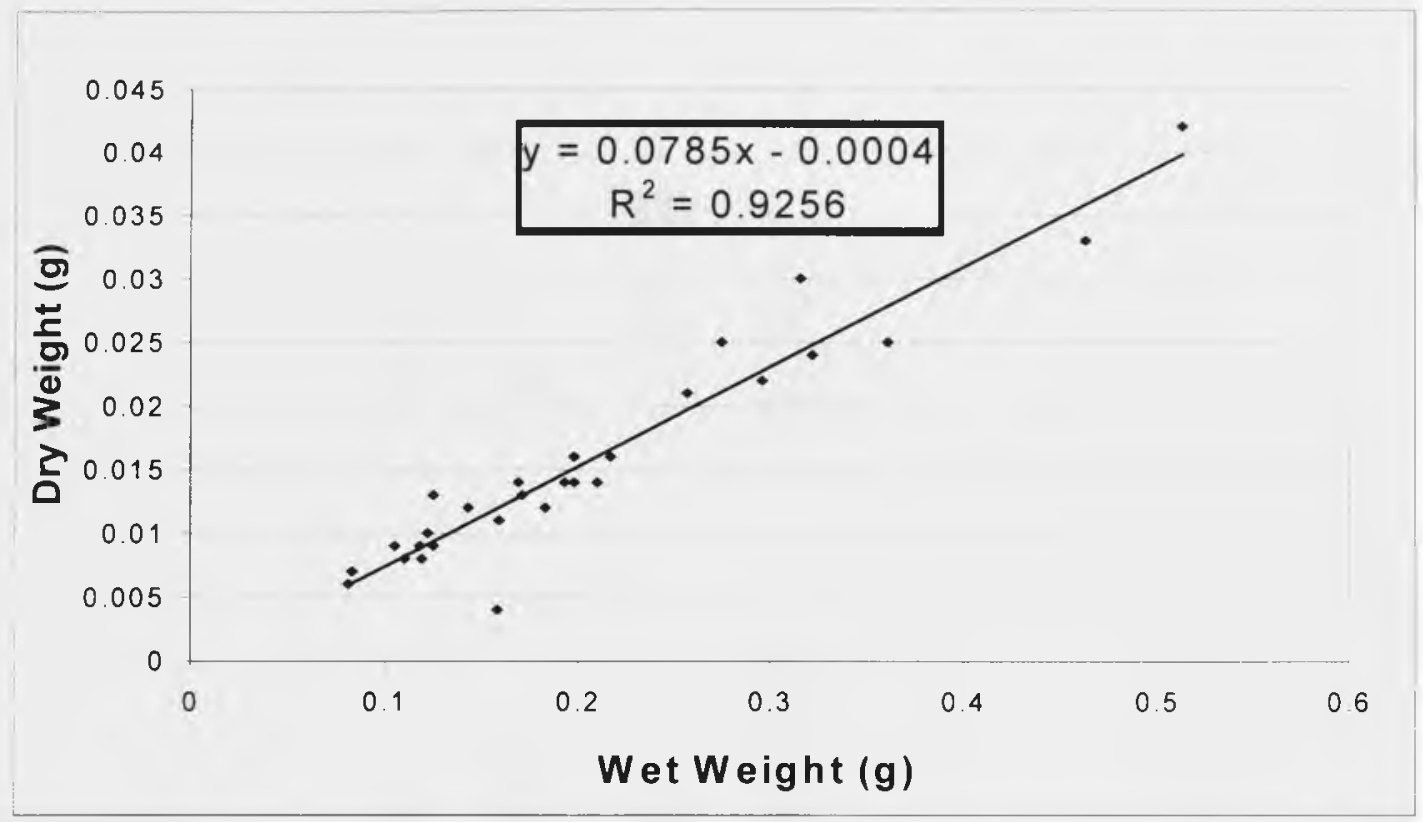

Figure 3. Temperature during the six independent subzero freezes.

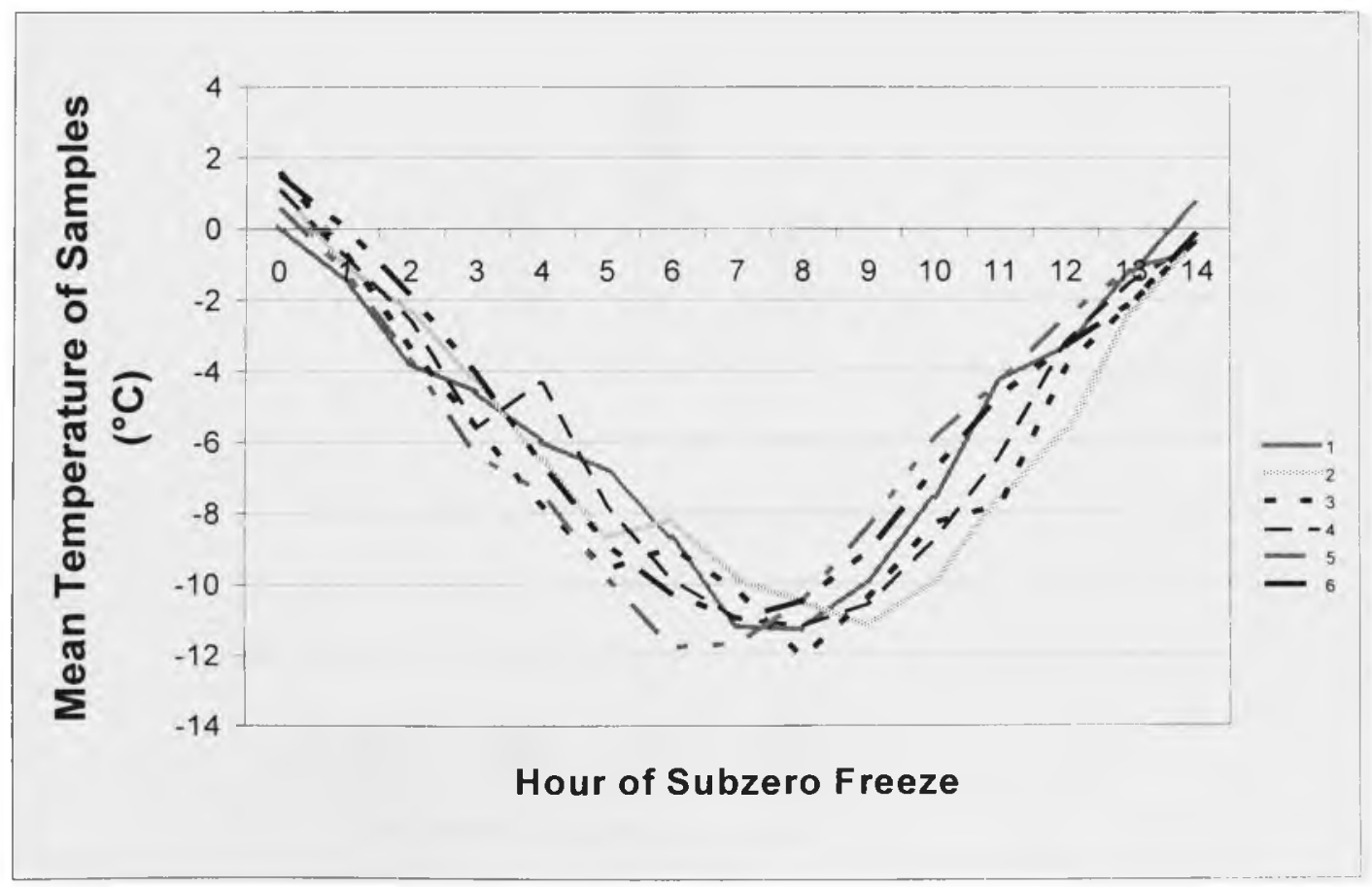


Figure 4. Growth response to four light-temperature environments: a) mean change in net dry weight; b) mean net elongation of main branches c) mean total number of new branches per sample; d) mean total new branch net elongation per sample.

a.

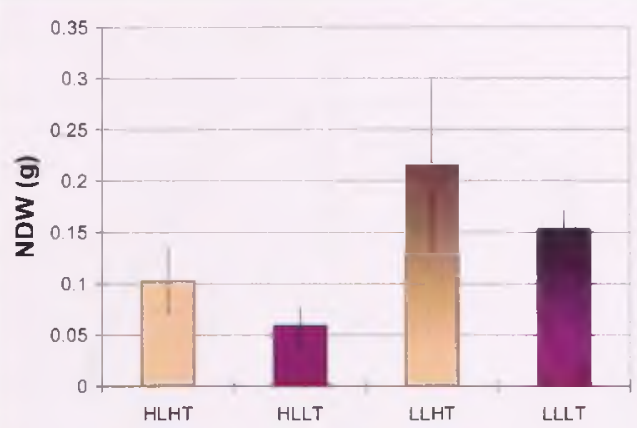

b.

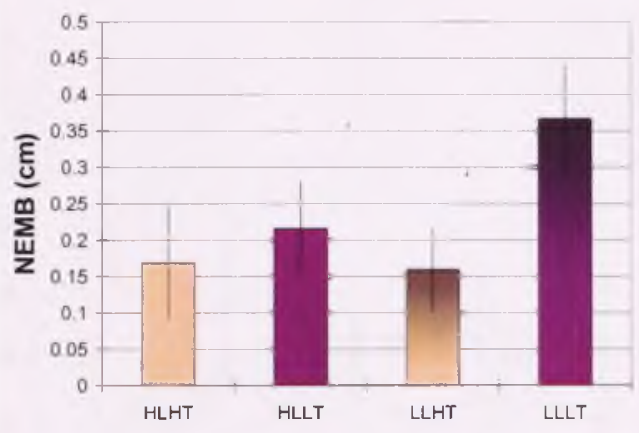

c.

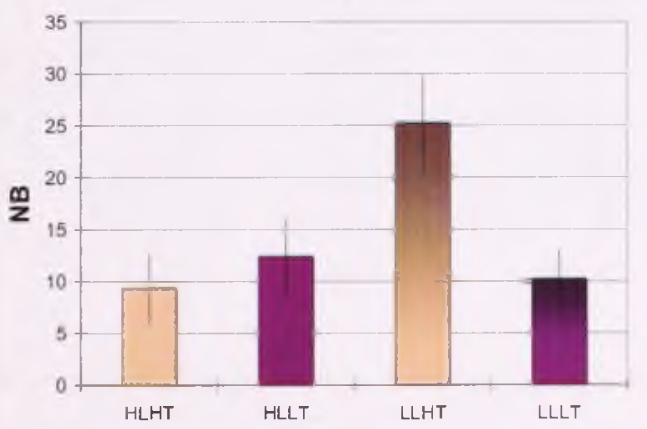

d.

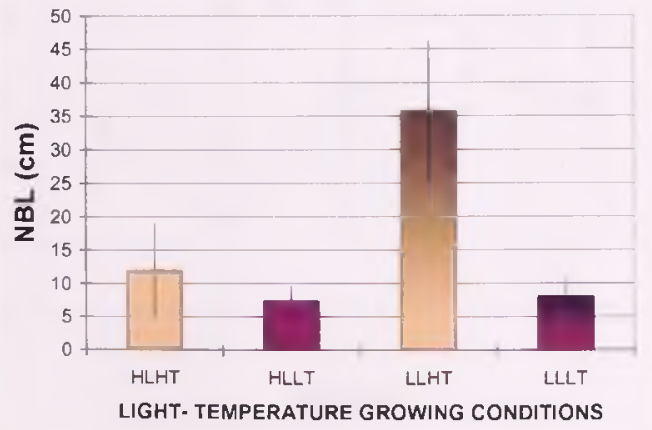


Figure 5. Physiological response to four light-temperature environments over 5 weeks: a) GPP $\left(\mu \mathrm{mol} / \mathrm{m}^{-2} / \mathrm{s}^{-1}\right)$; b) Yield; c) $\mathrm{F}_{\mathrm{v}} / \mathrm{F}_{\mathrm{m}}$.

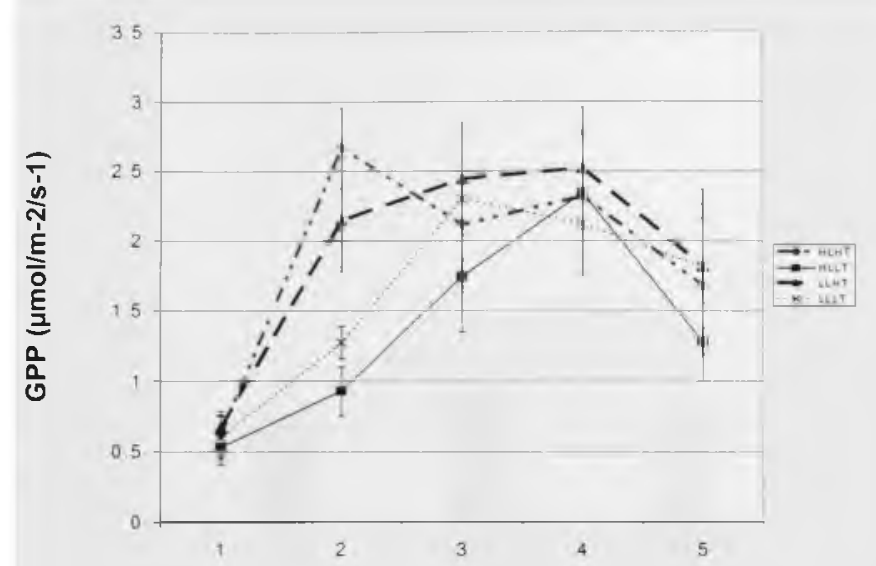

a.

b.
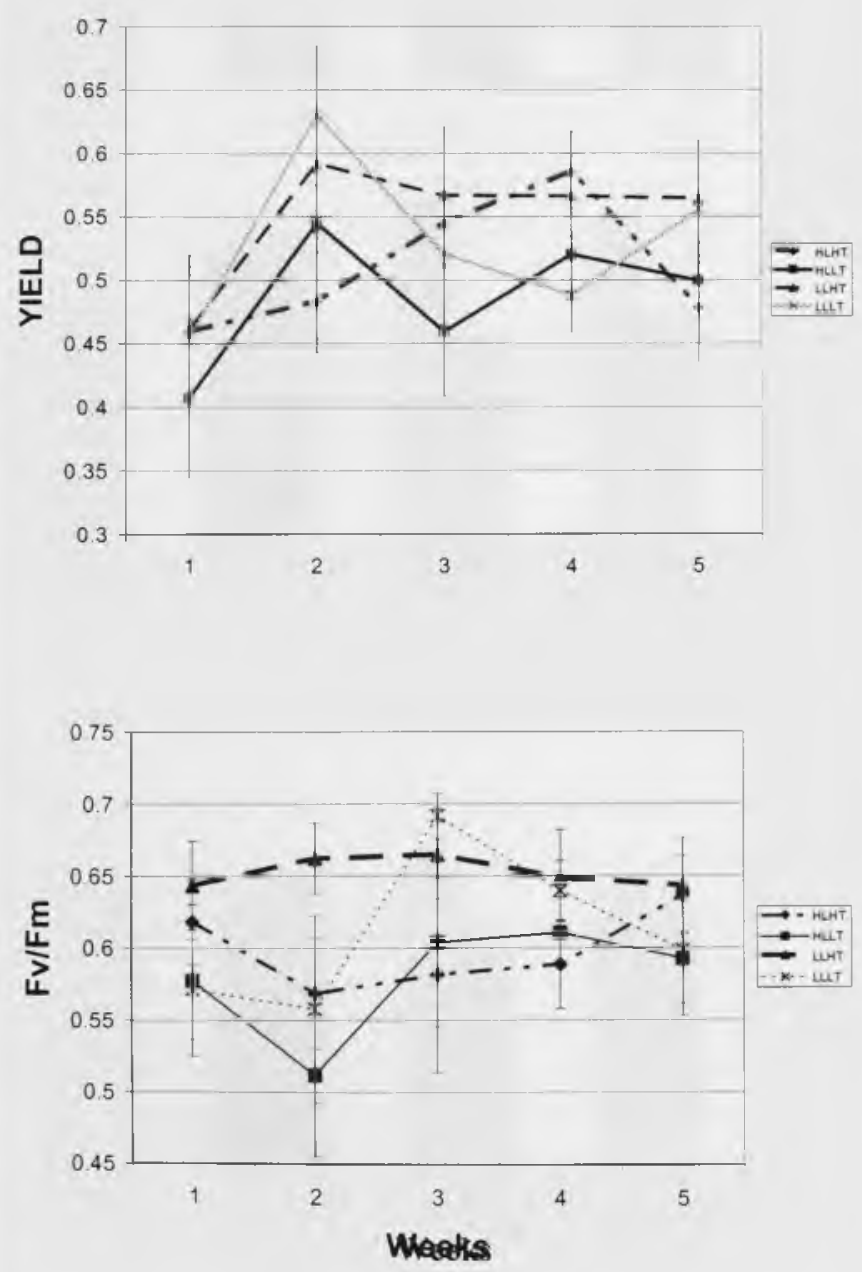
Figure 6. Short-term freeze effect on four light-temperature acclimation conditions: a) GPP $\left(\mu \mathrm{mol} / \mathrm{m}^{-2} / \mathrm{s}^{-1}\right)$ b) Yield c) $\mathrm{F}_{\mathrm{v}} / \mathrm{F}_{\mathrm{m}}$. All measurements were taken at $6^{\circ} \mathrm{C}$.
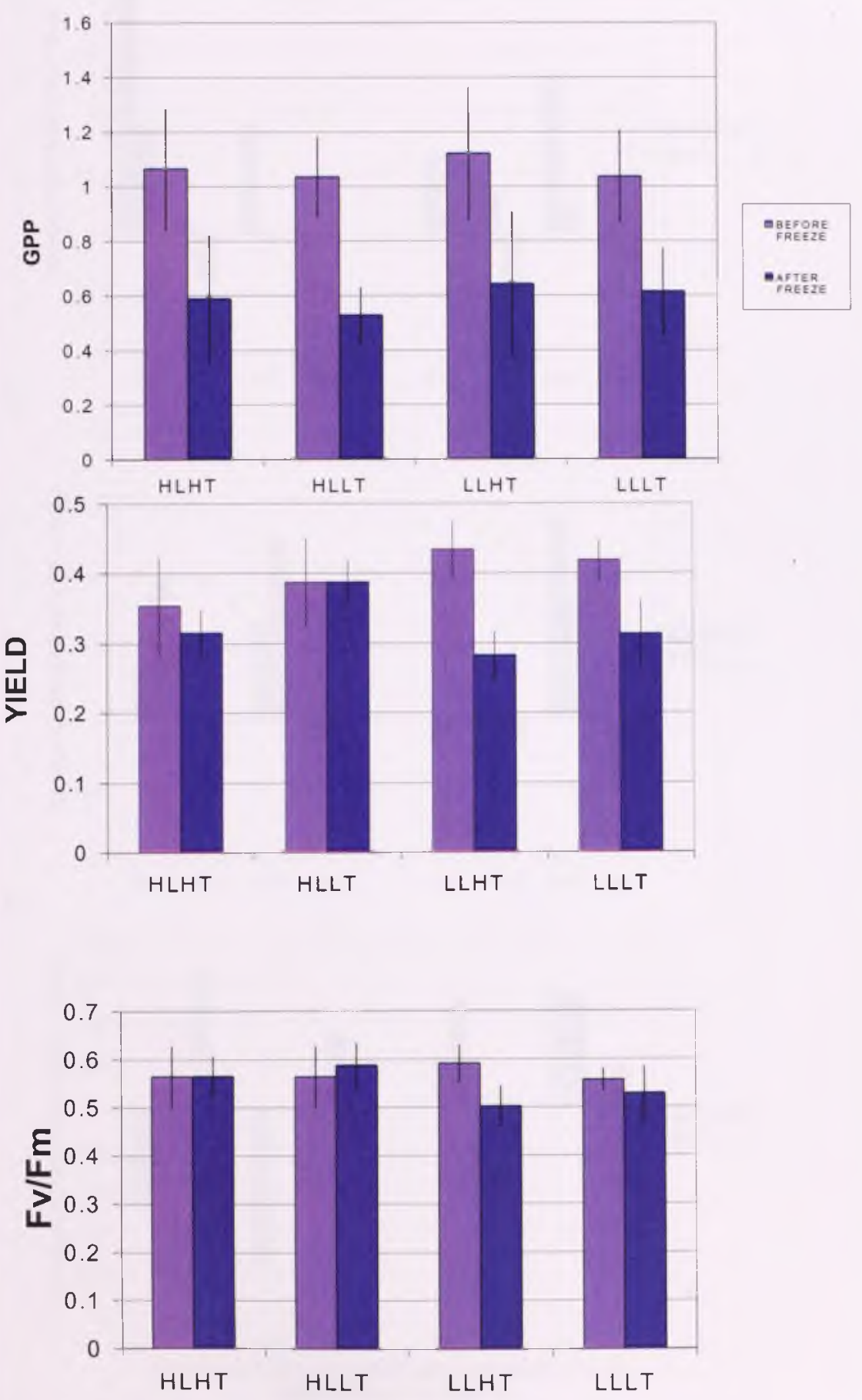

SHORT-TERM FREEZE EFFECT ON 4 LIGHT.

TEMPERATURE CONDITIONS 
Figure 7. Recovery after FTE shown as measurements 1-Day before FTE minus post Day 5 and post Day 14: a) Gross Primary Productivity $\left(\mu \mathrm{mol} / \mathrm{m}^{-2} / \mathrm{s}^{-1}\right)$ b) YIELD c) $\mathrm{F}_{\mathrm{v}} / \mathrm{F}_{\mathrm{m}}$. All measurements were taken at $18^{\circ} \mathrm{C}$.

a.

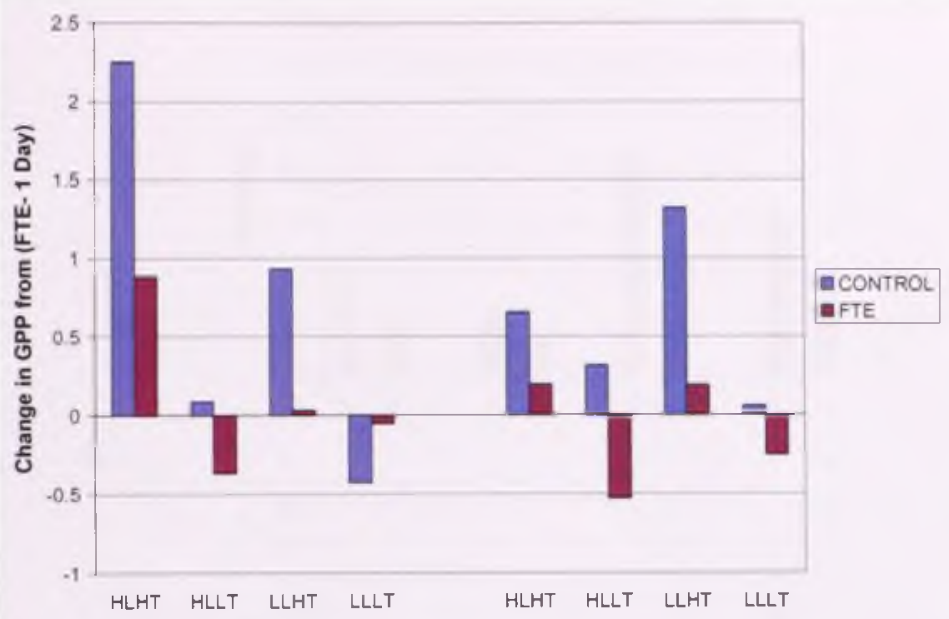

b.
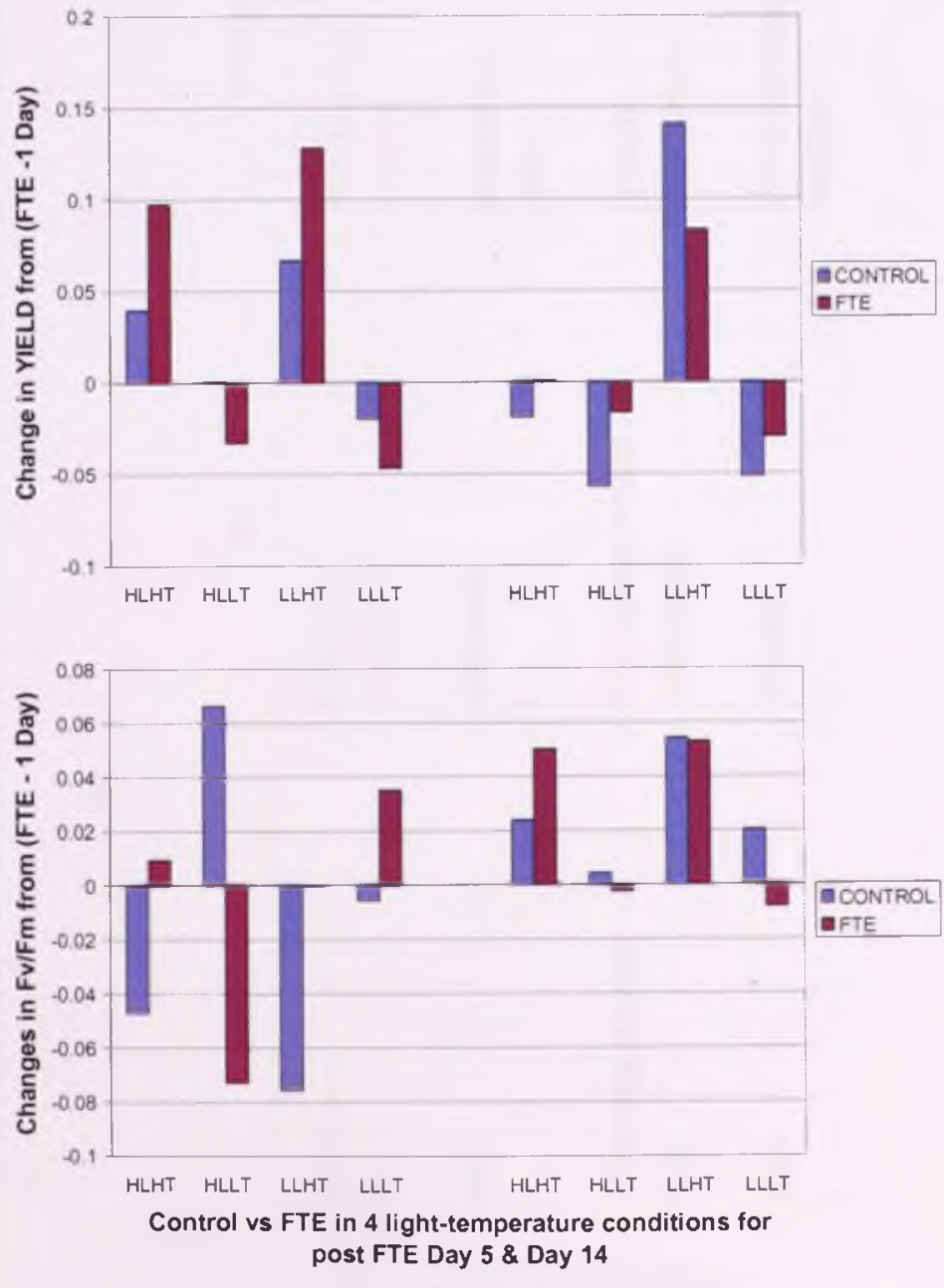

C. 
Figure 8. Freeze effect on the growth response under 4 light-temperature environments: a) mean change in net dry weight; b) mean main branch net elongation; c) mean total number of new branches per sample; d) mean total new branch net elongation per sample.

a.

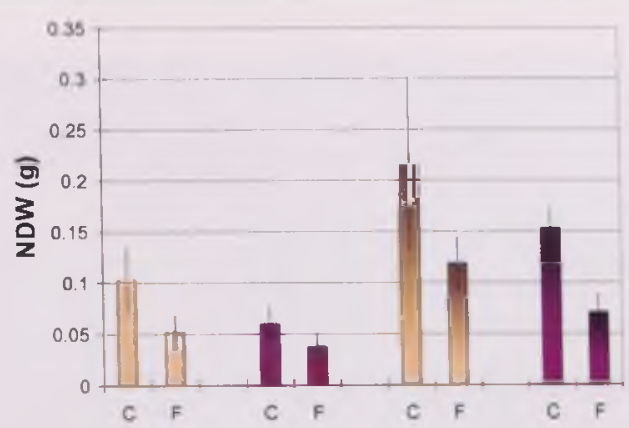

b.

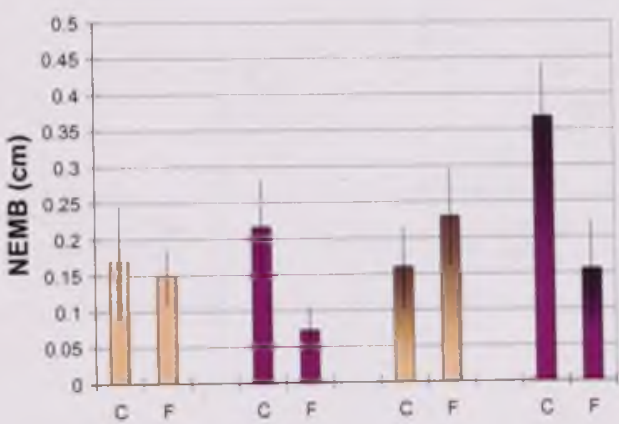

c.

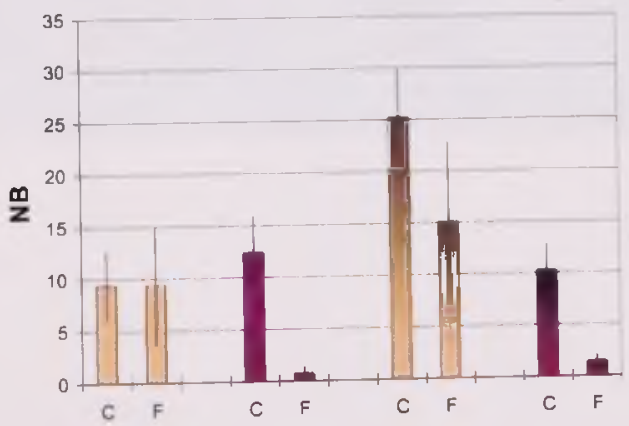

d.

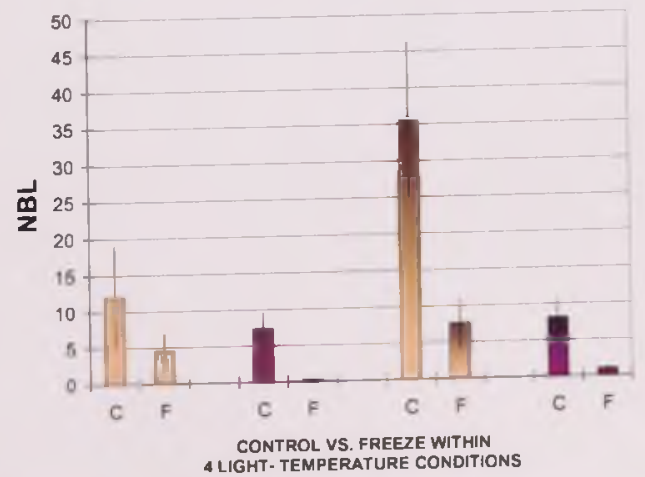


Figure 9. Warmer Climate: Sphagnum Loses the Ecosystem Engineering Ability. Community interactions that have been allowing Sphagnum to minimize vegetative cover may reach a threshold in which the interaction of the physiology of Sphagnum and vascular plants will promote a switch to a LLHT understory as the Arctic warms.

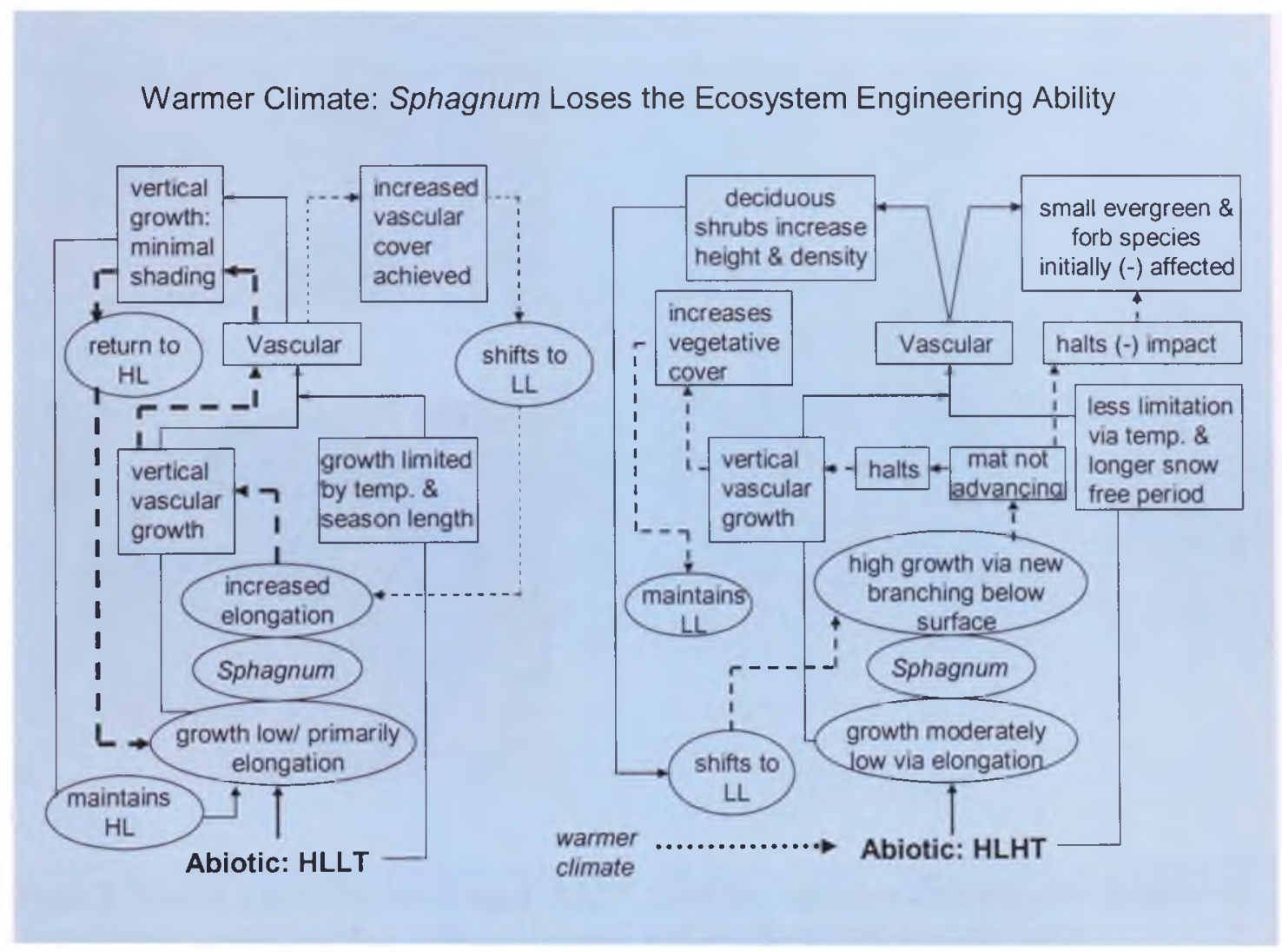


Plate 1: Contrasting color of Sphagnum girgensohnii: a) characteristic green color produced in growth chambers; b) brown color with green specks found in situ.

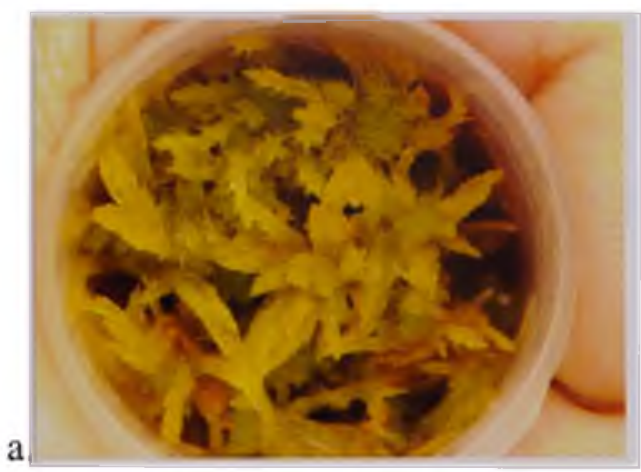

b

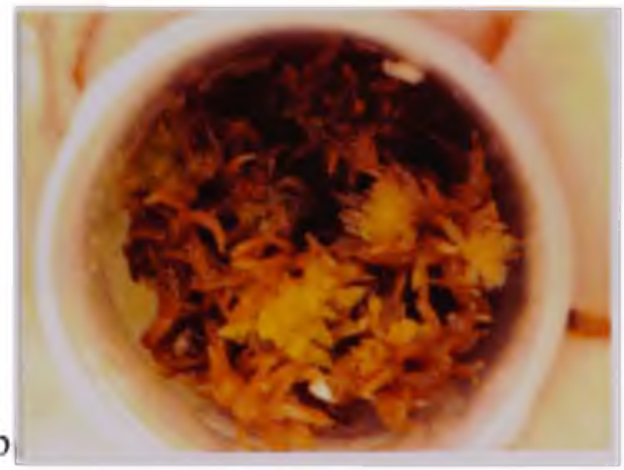

Plate 2: Toolik Lake, Brooks Range, AK: Collection location. Eriophorum vaginatum, Betula nana, Salix pulchra, and Sphagnum species dominate ground cover.

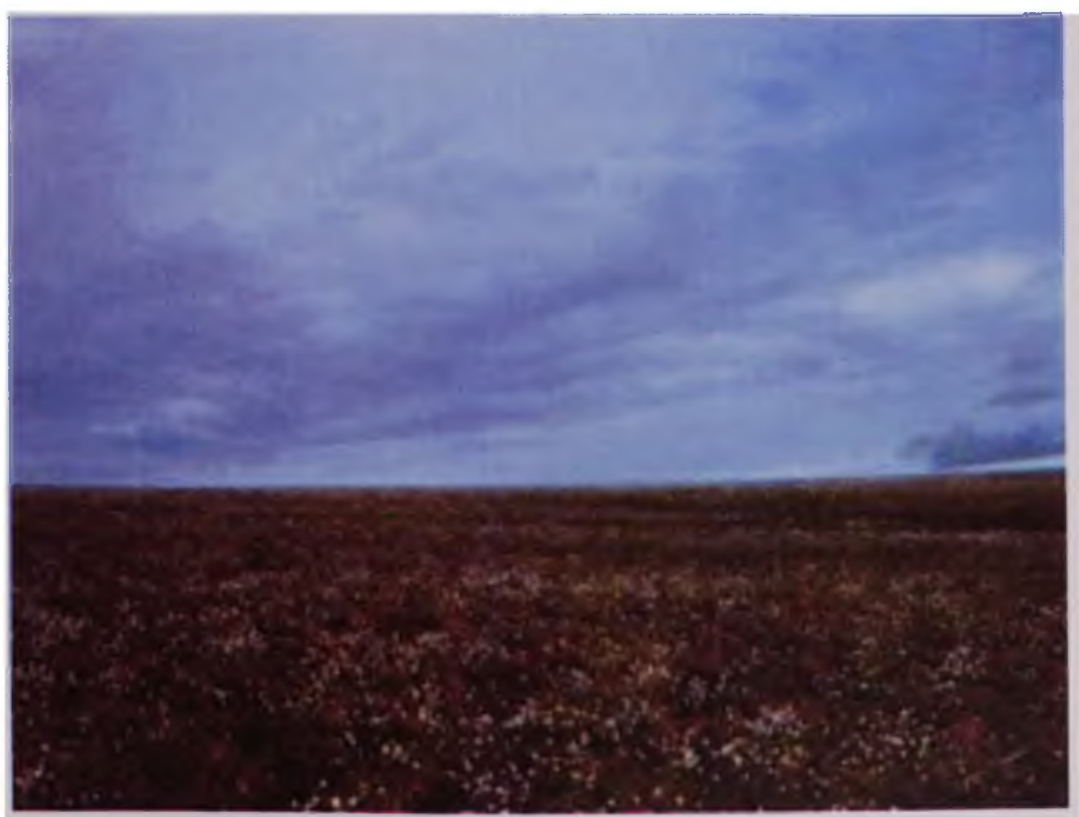


Plate 3: Freeze-thaw event set-up. Plants samples attached to individual thermocouples are approaching freezing conditions under ice.

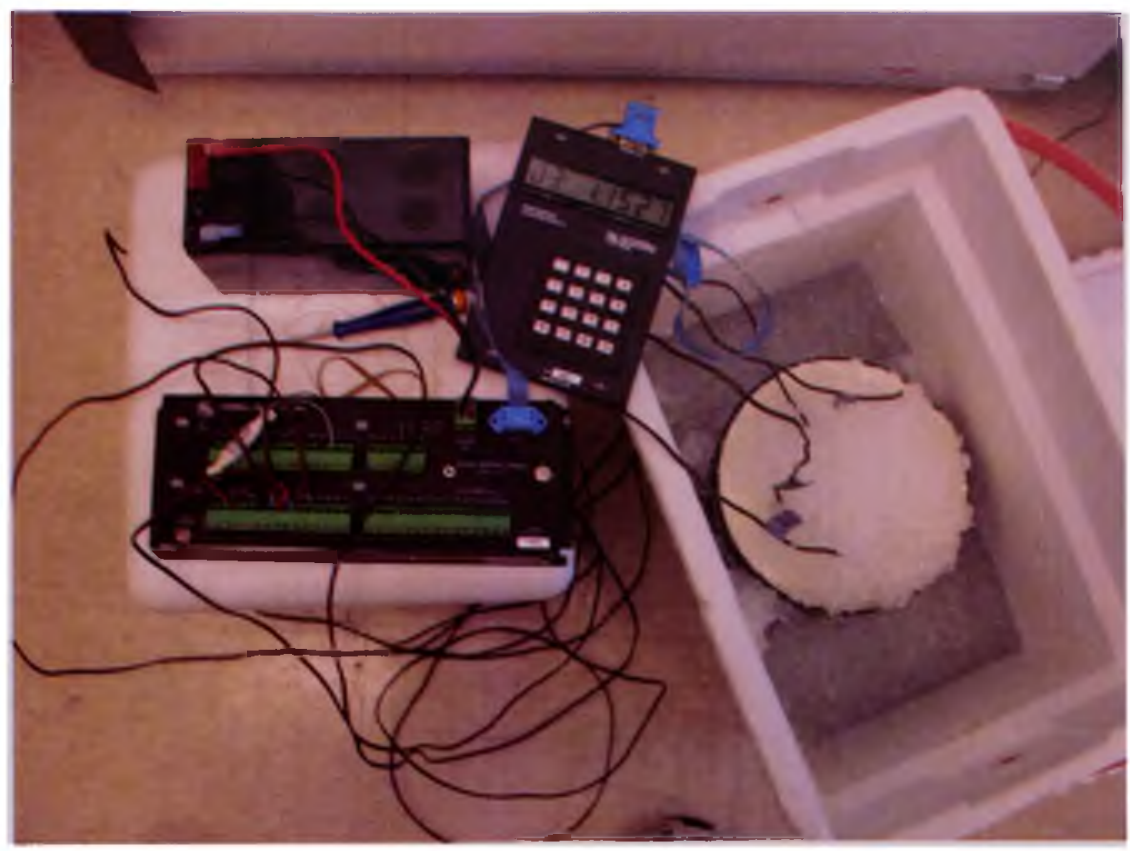


Plate 4: Examples of growth from 4 light-temperature environments. Sphagnum grown in a) HLHT; b) HLLT; c) LLHT; d) LLLT.
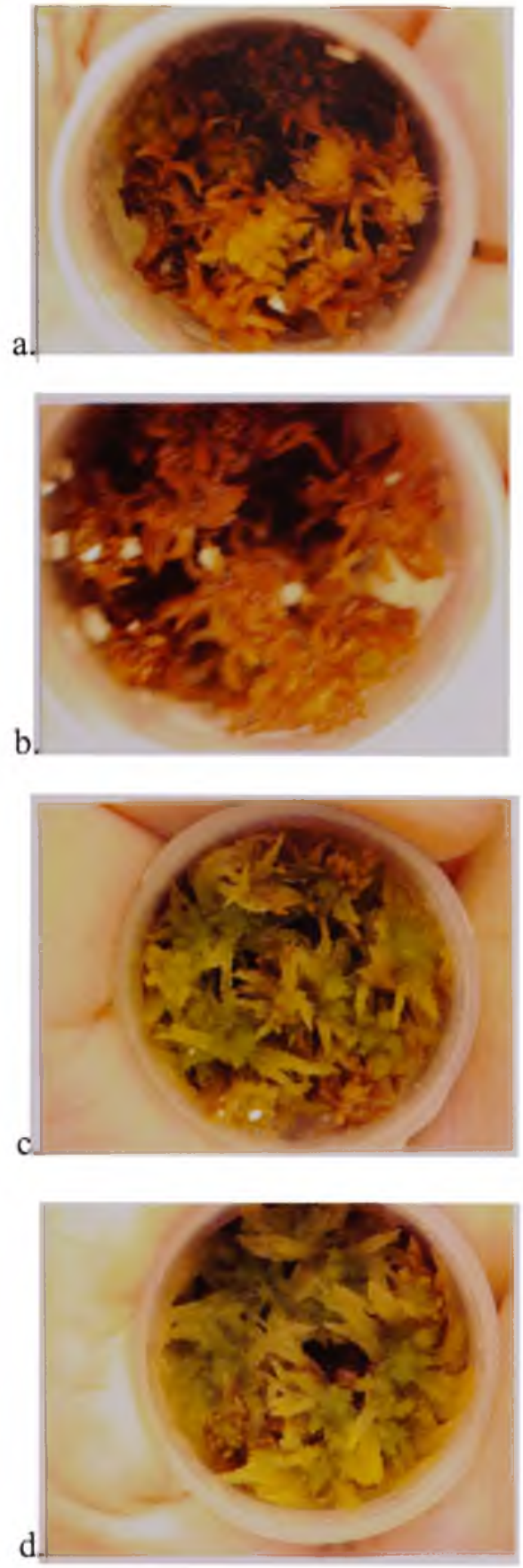
Plate 5: Sphagnum branches produced in the low-light, high-temperature environment

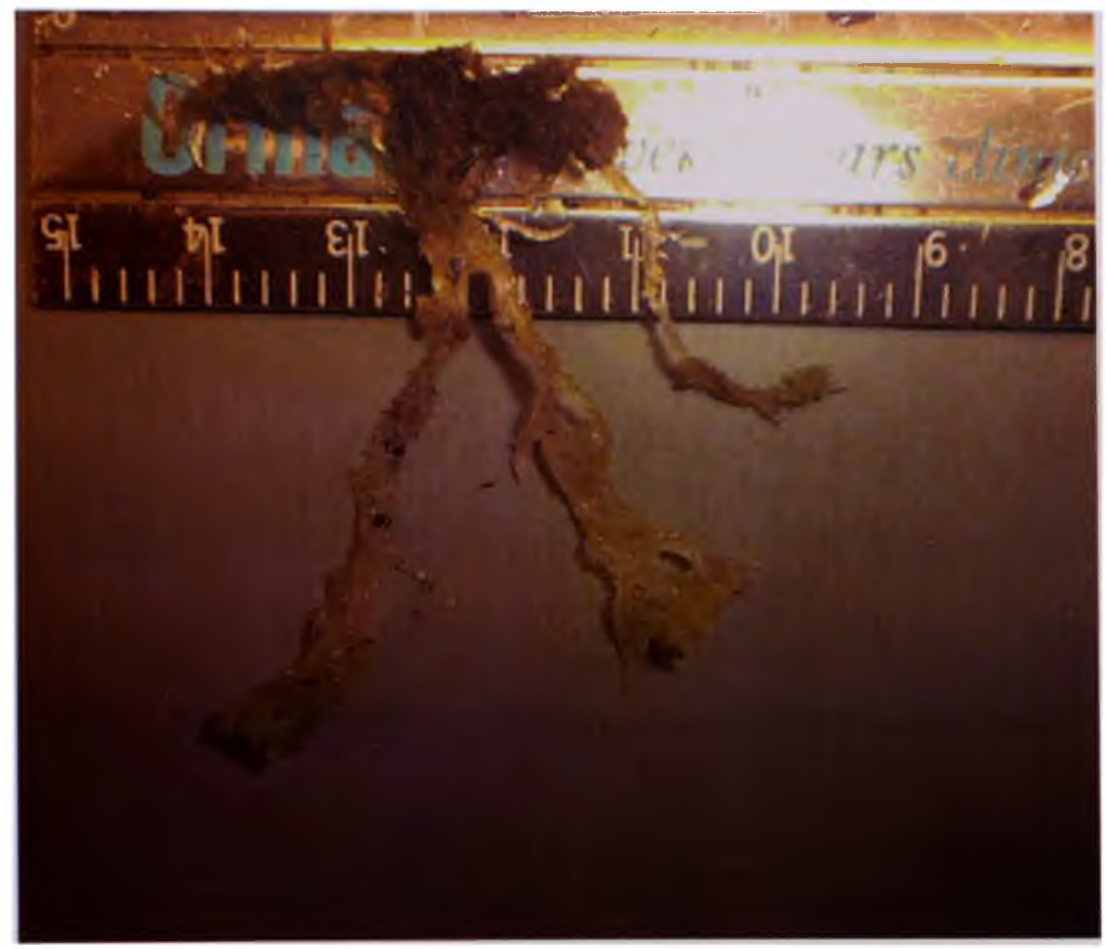


Plate 6: Loss of chlorophyll in the tender new shoots due to the freeze-thaw event

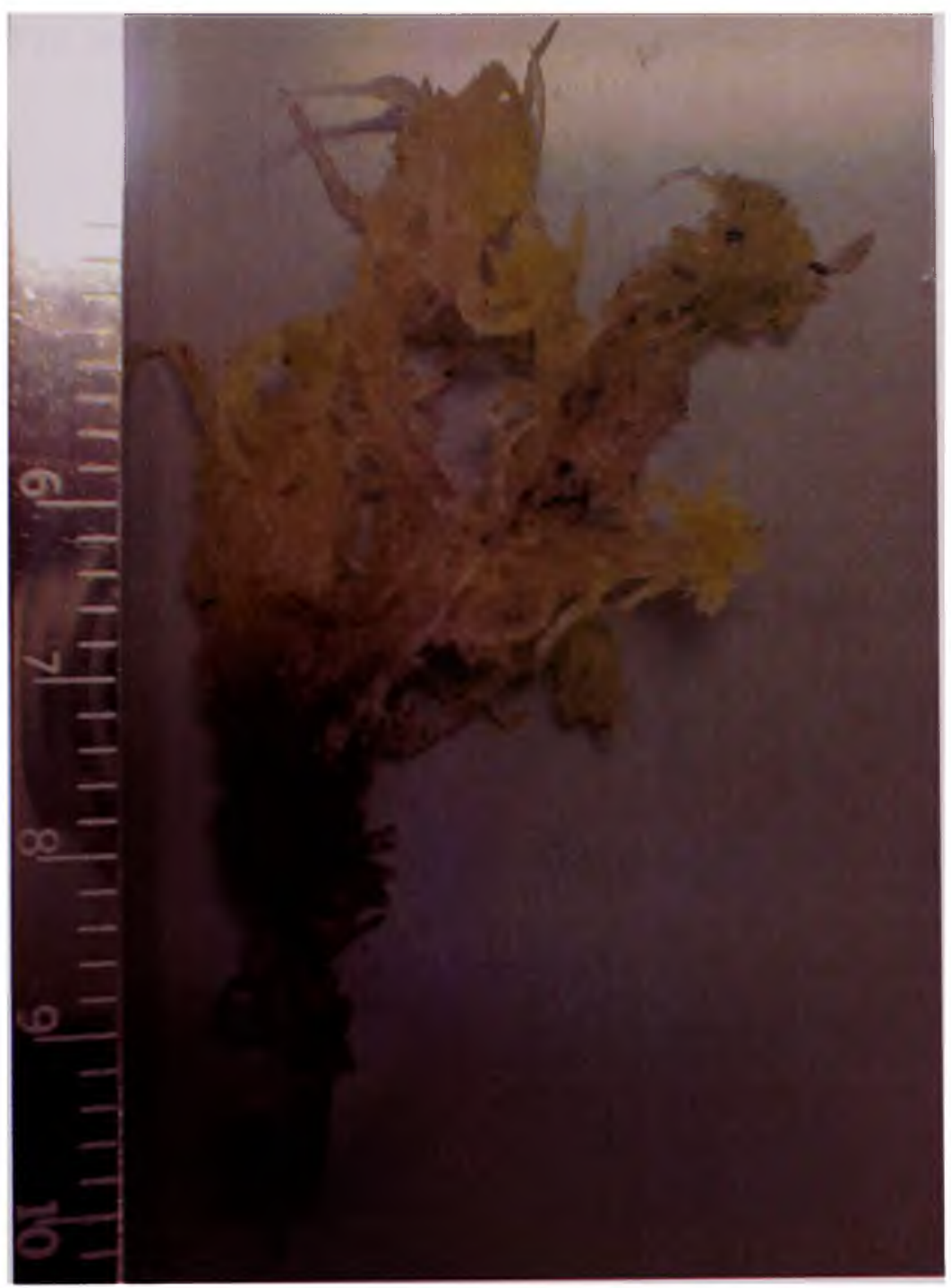


Plate 7: Sphagnum girgensohnii Russowi under 300X S.E.M. Hyaline cells line the outside of the plant, holding water and nutrients, freezing taking place here first during FTE could serve as protection to the rest of the plant.

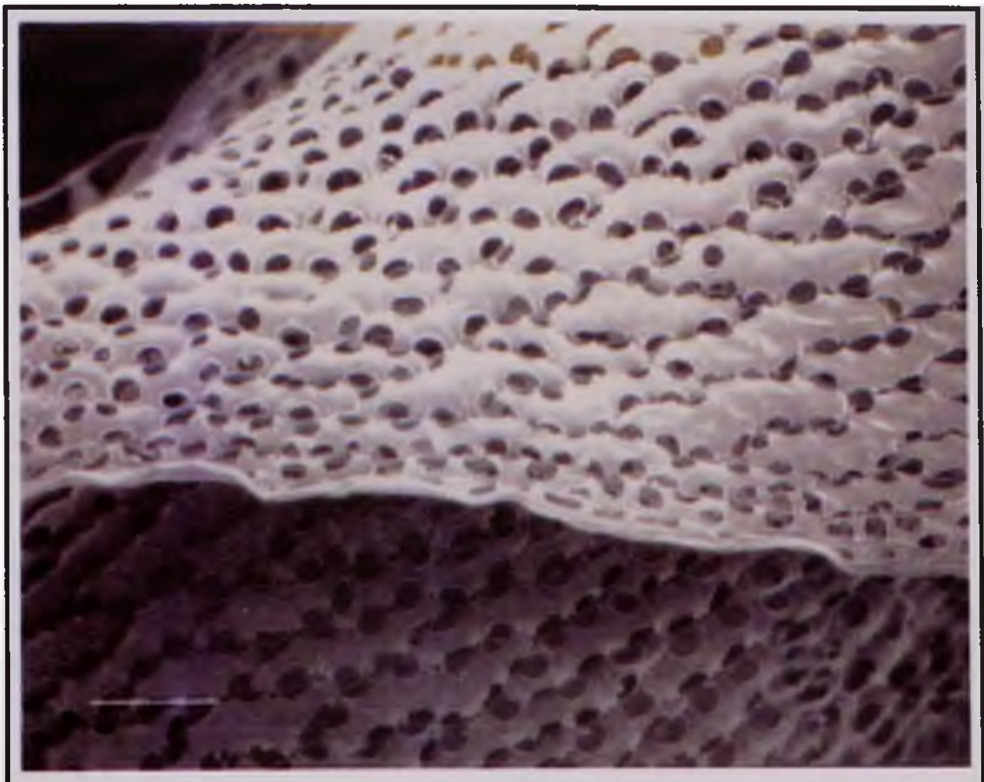

$300 X$ 


\section{REFERENCES}

Aldous, A. R. (2002) "Nitrogen retention by Sphagnum mosses: responses to atmospheric nitrogen deposition and drought." Canadian Journal of Botany 80: 721-731.

Andrus, R. E., Karlin, E.F. \& Talbot, S.S. (1992). "Rare and endangered Sphagnum species in North America." Biological Conservation 59 (2-3): 247-254.

Arft, A. M., Walker, M.D., Gurevitch, J., Alatalo, J.M., Bret-Harte, M.S., Dale, M., Diemer, M., Gugerli, F., Henry, G.H.R., Jones, M.H., Hollister, R.D., Jonsdottir, I.S., Laine, K., Levesque, E., Marion, G.M., Molau, U., Molgaard, P., Nordenhall, U., Raszhivin, V., Robinson, C.H., Starr, G., Stenstrom, A., Stenstrom, M., Totland, O., Turner, P.L., Walker, L.J., Webber, P.J., Welker, J.M., \& Wookey, P.A. (1999). "Responses of tundra plants to experimental warming: meta-analysis of the international tundra experiment." Ecological Monographs 69 (4): 491-511.

Balagurova, N., Drozdov, S., \& Grabovik, S. (1996) "Cold and heat resistance of five species of Sphagnum." Annales Botanici Fennici 33 (1): 33-37.

Berendse, F., N. V. Breemen, H. Rydin, A. Bultler, M. Heijmans, M. R. Hoosbeek, J.A. Lee, E. Mitchell, T. Saarinen, H. Vansander, B. Wallen. (2001). "Raised atmospheric $\mathrm{CO}_{2}$ levels and increased $\mathrm{N}$ deposition cause shifts in plant species composition and production in Sphagnum bogs." Global Change Biology 7:591598.

Chapin, F. S. (1992). "Arctic ecosystems in a changing climate: an ecophysiological perspective”. In Chapin III, F.S., Jefferies, R.L., Reynolds, J.F., Shaver, G.R. \& Svoboda, J. (eds.), Arctic Ecosystems in a Changing Climate. San Diego: Academic Press. 35-57.

Clymo, R. S. (1970). "The growth of Sphagnum: methods and measurements." Journal of Ecology 58(1): 13-49.

Clymo, R. S. (1973). "The growth of Sphagnum: some effects of environment.” Journal of Ecology 61(3): 849-869.

Clymo, R. S. and Hayward, P. M. (1982). "The ecology of Sphagnum." In Bryophyte Ecology, (ed. A. J. E. Smith), pp. 229-289. Chapman and Hall, London.

Clymo, R.S. \& Duckett, J.G. (1986) "Regeneration of Sphagnum." New Phytologist 102(4): 589-614. 
Deltoro, V.I., Calatayud, A., Morales, F., Abadia, A. \& Barreno, E. (1999). "Changes in net photosynthesis, chlorophyll fluorescence and xanthophyll cycle interconversions during freeze-thaw cycles in the Mediterranean moss Leucodon sciuroides." Oecologia 120: 499-505.

Dilks, T.J.K. \& Proctor, M.C.F. (1975) "Comparative experiments on temperature responses on bryophytes - assimilation, respiration and freezing damage." Journal of Bryology 8: 317-336.

Dore, M.H.I. (2005). "Climate change and changes in global precipitation patterns: What do we know?" Environmental International 31(8): 1167-1181.

Gerdol, R., Bonora, A., Marchesini, R., Gualandri, R. \& Pancaldi, S. (1998). "Growth response of Sphagnum capillifolium to nighttime temperature and nutrient level: mechanisms and implications for global change." Arctic and Alpine Research 30(4): 388-395.

Gorham, E. (1991). "Northern peatlands: role in the carbon cycle and probable responses to climate warming." Ecological Applications 1(2): 182-195.

Gorsuch, D.M. \& Oberbauer, S.F. (2002). "Effect of mid-season frost and elevated growing season temperature on stomatal conductance and specific zylem conductivity of the arctic shrub, Salix pulchra." Tree Physiology 22: 1027-1034)

Grosvernier, P., Matthey, Y. \& Buttler, A. (1997). "Growth potential of three Sphagnum species in relation to water table level and peat properties with implications for their restoration in cut-over bogs." Journal of Applied Ecology 34(2): 471-483.

Gunnarsson, U. \& Rydin, H. (2000). "Nitrogen fertilization reduces Sphagnum production in bog communities." New Phytologist 147(3): 527-537.

Harley, P. C., Tenhunen, J.D., Murray, K.J. \& Beyers, J (1989). "Irradiance and temperature effects on photosynthesis of tussock tundra Sphagnum mosses from the foothills of the Philip Smith Mountains, Alaska." Oecologia. 79(2): 251-259.

Hastings, S. J., Luchessa, S.A., Oechel, W.C., \& Tenhunen, J.D. (1989). "Standing biomass and production in water track drainages of the foothills of the Philip Smith Mountains, Alaska." Holarctic Ecology 12: 304-311.

Hayward, P.M. \& Clymo, R.S. (1983). "The growth of Sphagnum - experiments on, and simulation of, some effects of light-flux and water-table depth." Journal of Ecology 71(3): 845-863. 
Heijmans, M., Arp, W.J. \& Berendse, F. (2001). "Effects of elevated carbon dioxide and increased nitrogen deposition on bog vegetation in the Netherlands." Journal of Ecology 89(2): 268-279.

Hicklenton, P.R. \& Oechel, W.C. (1976). "Physiological aspects of ecology of Dicranum-fuscescens in subarctic. 1. Acclimation and acclimation potential of CO2 exchange in relation to habitat, light, and temperature." Canadian Journal of Botany 54(10): 1104-1119.

Hinzman, L.D., Bettez, N.D., Bolton, W.R., Chapin, F.S., Dyurgerov, M.B., Fastie, C.L., Griffith, B., Hollister, R.D., Hope, A., Huntington, H.P., Jensen, A.M., Jia, G.J., Jorgenson, T., Kane, D., Klein, D.K., Kofinas, A.D., Lynch, A.H., Llyod, A.H., McGuire, A.D., Nelson, F.E., Oechel, W.C., Osterkamp, T.E., Racine, C.H., Romanovsky, V.E., Stone, R.S., Stow, D.A., Sturm, M., Tweedie, C.E., Vourlitis, G.L., Walker, M.D., Walker, D.A., Webber, P.J., Welker, J.M., Winker, K.S. \& Yoshikawa, K. (2005). "Evidence and implications of recent climate change in northern Alaska and other arctic regions." Climate Change 72: 251-298.

Hobbie, S. E. (1996). "Temperature and plant species control over litter decomposition in Alaskan tundra." Ecological monographs 66(4): 503-522.

Hobbie, S. E., Shevtsova, A. \& Chapin, F.S. (1999). "Plant responses to species removal and experimental warming in Alaskan tussock tundra." Oikos 84(3): 417-434.

Hobbie, S.E., Schimel, J.P., Trumbore, S.E. \& Randerson, J.R. (2000). "Controls over carbon storage and turnover in high-latitude soils." Global Change Biology 6 (Suppl. upp): 196-210.

Hogg, P., Squires, P. \& Fitter, A.H. (1995). “Acidification, nitrogen deposition and rapid vegetational change in a small valley mire in Yorkshire." Biological Conservation 71(2): 143-153.

Hollister, R.D., Webber, P.J. \& Tweedie, C.E. (2005). "The response of Alaskan arctic tundra to experimental warming: differences between short- and long-term responses." Global Change Biology 11(4): 525-536.

Intergovernmental-Panel-of-Climate-Change (2001). "Climate Change 2001: The Scientific Basis" Cambridge, UK: Cambridge University Press.

Intergovernmental-Panel-of-Climate-Change (2007). "The Physical Science Basis" Cambridge, UK: Cambridge University Press.

Jauhiainen, J., Silvola, J. \& Vasander, H. (1998). “The effects of increased nitrogen deposition and $\mathrm{CO}_{2}$ on Sphagnum angustifolium and $S$. warnstorfii." Annales Botanici Fennici 35(4): 247-256. 
Jorgenson, M.T., Shur, Y.L. \& Pullman, E.R. (2006) "Abrupt increase in permafrost degradation in Arctic Alaska." Geophysical Research Letters 33(2): L02503.

Kane, D. L., Hinzman, L.D., Woo, M. \& Everett, K.R. (1992). “Arctic hydrology and climate change." Arctic Ecosystems in a Changing Climate. F. S. Chapin, III, et al. San Diego, Academic Press, Inc: 35-57.

Keeling, C. D., Chin, J.F.S. \& Whorf, T.P. (1996). "Increased activity of northern vegetation inferred from atmospheric $\mathrm{CO}_{2}$ measurements." Nature 382(6587): 146-149.

Kennedy, A.D. (1993). "Photosynthetic response of the Antarctic moss Polytrichumalpestre Hoppe to low-temperatures and freeze-thaw stress." Polar Biology 13(4): 271-279.

Koprivnjak, J.F. \& Moore, T.R. (1992). "Sources, sinks, and fluxes of dissolved organic carbon in subarctic fen catchments." Arctic and Alpine Research 24 (3): 204-210.

Kullman, L. (2002) "Rapid recent range-margin rise of tree and shrub species in the Swedish Scandes.” Journal of Ecology 90(1): 68-77.

Longton, R.E. (1992). "The role of bryophytes and lichens in terrestrial ecosystems." In Bryophtes and Lichens in a Changing Environment. (ed. J. W. Bates and A. M. Farmer) 32-76 Oxford University Press, Oxford.

Lovelock, C.E., Jackson, A.E., Melick, D.R. \& Seppelt, R.D. (1995) "Reversible photoinhibition in antarctic moss during freezing and thawing." Plant Physiology 109: $955-961$.

Mäkipää, R. \& Heikkinen, J. (2003) "Large-scale changes in adundance of terricolous bryophytes and macrolichens in Finland." Journal of Vegetation Science 14: 497508.

Malmer, N., Svensson, B.M. \& Wallen, B. (1994). "Interactions between Sphagnum mosses and field layer vascular pints in the development of peat-forming systems." Folia Geobotanica \& Phytotaxonomica 29(4): 483-496.

Marion, G.M., Bockheim, J.G. \& Brown, J (1997). “Arctic soils and the ITEX experiment." Global Change Biology 3(Suppl. 1): 33-43.

Maxwell, B. (1992). Arctic Climate: Potential for Change under Global Warming. Arctic Ecosystems in a Changing Climate. F. S. Chapin, III, et al. San Diego, Academic Press, Inc: 11-34. 
Mazur, P. (1969). "Freeze injury in plants." Annual Review of Plant Physiology 20: 419 448.

Mitchell, E.A., Buttler, A., Grosvernier, P., Rydin, H., Siegenthaler, A. \& Gobat, J.M. (2002) "Contrasted effects of increased $\mathrm{N}$ and $\mathrm{CO}_{2}$ supply on two keystone species in peatland restoration and implications for global change." Journal of Ecology 90: 529-533.

Moorhead, D.L. \& Reynolds J.F. (1993). "Effects of climate change on decomposition in Arctic tussock tundra: A modeling synthesis." Arctic and Alpine Research 25(4): 403-412.

Muller, C.H. (1952). "Plant succession in arctic heath and tundra in northern Scandinavia." Bulletin of the Torrey Botanical Club 79: 296-309.

Mulligan, R.C. \& Gignac, L.D. (2001) "Bryophyte community structure in a boreal poor fen: reciprocal transplants." Canadian Journal of Botany 79: 404-411.

Mulligan, R.C. \& Gignac, L.D. (2002) "Bryophyte community structure in a boreal poor fen II: interspecific competition among five mosses." Canadian Journal of Botany 80(4): 330-339.

Murray, K. J., Tenhunen, J.D. \& Kummerow, J. (1989) "Limitation on Sphagnum growth and net primary production in the foothills of the Philip Smith Mountains, Alaska." Oecologia 80: 256-262.

Murray, K. J., Tenhunen, J.D. \& Nowak, R.S. (1993). "Photoinhibition as a control on photosynthesis and production of Sphagnum mosses." Oecologia 96(2): 200-207.

Oberbauer, S.F. \& Starr, G. 2002. The role of anthocyanins for photosynthesis of Alaskan arctic evergreens during snow melt. Advances in Botanical Research 37: 129-145.

Oberbauer, S.F., Starr, G. \& Pop, E.W. 1998. "Effects of extended growing season and soil warming on carbon dioxide and methane exchange of tussock tundra in Alaska." Journal of Geophysical Research 103:29075-29082

Oechel, W. C., Hastings, S.J., Vourlitis, G., Jenkins, M., Riechers, G. \& Grulke, N. (1993). "Recent change of Arctic tundra ecosystems from a net carbon dioxide sink to a source." Nature 361(6412): 520-523.

Oechel, W.C. \& Vourlitis, G.L. (1994). "The effects of climate change on landatmosphere feedbacks in arctic tundra regions." Trends in Ecology \& Evolution 9(9): 324-329 
Ohlson, M., Okland, R.H., Nordbakken, J. \& Dahlberg, B. (2001). "Fatal interactions between Scots pine and Sphagnum mosses in bog ecosystems." Oikos 94: 425432.

Pannewitz, S., Schlensog, M., Green, T.G.A., Sancho, L.G. \& Schroeter, B. (2004). “Are lichens active under snow in continental Antarctica?" Oecologia 135: 30-38.

Repo, T., Hänninen, H., \& Kellomäki, S. (1996). "The effects of long-term elevation of air temperature and $\mathrm{CO}_{2}$ on the frost hardiness of Scots pine." Plant, Cell \& Environment 19: 209-216.

Roy, V., Ruel, J.C. \& Plamondon, A.P. 2000. "Establishment, growth and survival of natural regeneration after clearcutting and drainage on the forested wetlands." Forest Ecology and Management 129: 253-267.

Searles, P.S., Flint, S.D., Diaz, S.B., Rousseaux, M.C., Ballare, C.L. \& Caldwell, M.M. (2002) "Plant response to solar ultraviolet-B radiation in a southern South American Sphagnum peatland.” Journal of Ecology 90: 704-713.

Serreze, M.C., Walsh, J.E., Chapin, F.S., Osterkamp, T., Dyurgerov, M., Romanovsky, V., Oechel, W.C., Morison, J., Zhang, T. \& Barry R.G. (2000). "Observational evidence of recent change in the northern high-latitude environment." Climate Change 46(1-2): 159-207.

Shaver, G. and J. Laundre. Daily Soil Temperature and Meteorological Data for Sites at Toolik Lake Alaska. 2003. Boulder, CO: National Snow and Ice Data Center/World Data Center for Glaciology. Digital media.

Skre, O. \& Oechel, W.C. (1981). "Moss functioning in different taiga ecosystems in interior Alaska." Oecologia 48: 50-59.

Starr, G., Oberbauer, S.F. \& Pop, E.W. (2000). "Effects of lengthened growing season and soil warming on the phenology and physiology of Polygonium bistorta." Global Change Biology 6(3): 357-369.

Stein, J., Proulx, S. \& Levesque, D. (1994). "Forest floor frost dynamics during spring snowmelt in a boreal forested basin." Water Resources Research 30(4): 995-1007.

Svensson, B. (1995). “Competition between Sphagnum fuscum and Drosera rotundifolia: A case of ecosystem engineering." Oikos 74(2) 205-212.

Taulavuori, K.M.J., Laine, K., Taulavuori, E.B., Pakonen, T. \& Saari, E. (1997) "Accelerated dehardening in the bilberry (Vaccinium myrtillus L.) induced by a small elevation in air temperature." Environmental Pollution 98: 91-95. 
Taulavuori, K.M.J., Taulavuori, E.B., Skre, O., Igeland, B. \& Laine, K.M. (2004)

"Dehardening of mountain birch (Betula pubescens ssp. czerepanovii) ecotypes at elevated winter temperatures." New Phytologist 162: 427-436.

Tenhunen, J.D., Lange, O.L., Hahn, S.C. ], Siegwolf, R. \& Oberbauer S.F. (1992) "The ecosystem role of poikilohydric tundra plants." In Chapin III, F.S., Jefferies, R.L., Reynolds, J.F., Shaver, G.R. \& Svoboda, J. (eds.), Arctic Ecosystems in a Changing Climate. San Diego: Academic Press. 193-237.

Van Breemen, N. (1995). "How Sphagnum bogs down other plants." Trends in Ecology \& Evolution 10(7): 270-275.

Van Der Heijden, E., Verbeek, S.K. \& Kuiper, P.J.C. (2000). "Elevated atmospheric $\mathrm{CO}_{2}$ and increased nitrogen deposition: effects on $\mathrm{C}$ and $\mathrm{N}$ metabolism and growth of the peat moss Sphagnum recurvum P. Beauv. var. mucronatum (Russ.) Warnst." Global Change Biology 6(2): 201-212.

Vavrus, S., Walsh, J.E., Chapman, W.L., Portis, D. (2006). "The behavior of extreme cold air outbreaks under greenhouse warming." International Journal of Climatology 26: 1133-1147.

Vitt, D.H., Halsey, L.A. \& Zoltai, S.C. (1994). "The bog landforms of continental western Canada in relation to climate and permafrost patterns." Arctic and Alpine Research 26(1): 1-13.

Waddington, J. M., Rotenberg, P.A. \& Warren, F.J. (2001). "Peat $\mathrm{CO}_{2}$ production in a natural and cutover peatland: Implications for restoration." Biogeochemistry 54(2): 115-130.

Walker, D. A., Binnian, E., Evans, B.E., Lederer, N.D., Nordstrand, E., Webber, P.J. (1989). "Terrian, vegetation, and landscape evolution of the R4D research site, Brooks Range Foothills, Alaska." Holarctic Ecology 12: 238-261.

Walker, M.D., Wahren, C.H., Hollister, R.D., Henry, G.H.R., Ahlquist, L.E., Alatalo, J.M., Bret-Harte, M.S., Calef, M.P., Callaghan, T.V., Carroll, A.B., Epstein, H.E., Jonsdottir, I.S., Klein, J.A., Magnusson, B., Molau, U., Oberbauer, S.F., Rewa, S.P., Robinson, C.H., Shaver, G.R., Suding, K.N., Thompson, C.C., Tolvanen, A., Totland, P.L., Turner, P.L., Tweedie, C.E., Webber, P.J. \& Wookey, P.A. (2006) "Plant community responses to experimental warming across the tundra biome." Proceedings $\mathrm{pf}$ the National Academy of Sciences of the United States of America 103(5): 1342-1346. 
Walker, M.D., Walker, D.A. \& Auerbach, N.A. (1994). "Plant- communities of a tussock tundra landscape in the Brooks Range Foothills, Alaska." Journal of Vegetation Science 5(6): 843-866.

Woo, M.K. \& Young, K.L. (2006). "High Arctic wetlands: their occurrence, hydrological characteristics and sustainability." Journal of Hydrology 320(3-4): 432-450. 